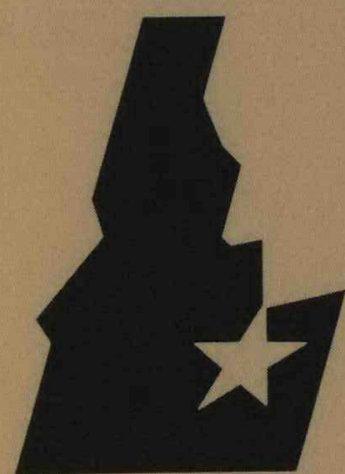

Idaho National

Engineering Laboratory

Managed

by the U.S.

Department

of Energy
EGG-EAST-8264

October 1988

\section{INFORMAL REPORT}

R. A. Callow

\begin{abstract}
THERMAL-HYDRAULIC RESPONSE AND IODINE
TRANSPORT DURING A STEAM GENERATOR TUBE

RUPTURE
\end{abstract}

\title{
LAN 031989
}

\section{REPRODUCED FROM BEST AVAILABLE COPY}

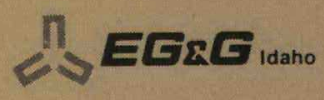

Work performed under DOE Contract No. DE-AC07-761D01570 


\section{DISCLAIMER}

Portions of this document may be illegible in electronic image products. Images are produced from the best available original document. 


\section{DISCLAIMER}

This book was prepared as an account of work sponsored by an agency of the United States Government. Neither the United States Government nor any agency thereof, nor any of their employees, makes any warranty, express or implied, or assumes any legal liability or responsibility for the accuracy, completeness, or usefulness of any information, apparatus, product or process disclosed, or represents that its use would not infringe privately owned rights. References herein to any specific commercial product, process, or service by trade name, trademark, manufacturer, or otherwise, does not necessarily constitute or imply its endorsement, recommendation, or favoring by the United States Government or any agency thereof. The views and opinions of authors expressed herein do not necessarily state or reflect those of the United States Government or any agency thereof.

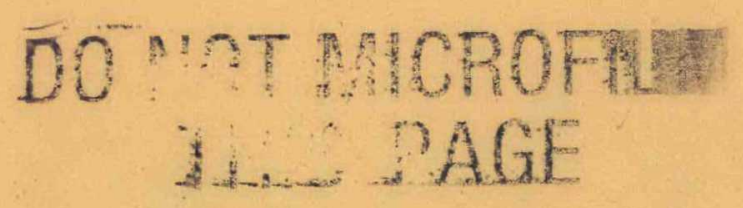




\title{
DISCLAIMER
}

This report was prepared as an account of work sponsored by an agency of the United States Government. Neither the United States Government nor any agency thereof, nor any of their employees, makes any warranty, express or implied, or assumes any legal liability or responsibility for the accuracy, completeness, or usefulness of any information, apparatus, product, or process disclosed, or represents that its use would not infringe privately owned rights. Reference herein to any specific commercial product, process, or service by trade name, trademark, manufacturer, or otherwise does not necessarily constitute or imply its endorsement, recommendation, or favoring by the United States Government or any agency thereof. The views and opinions of authors expressed herein do not necessarily state or reflect those of the United States Government or any agency thereof.

\section{THERMAL-HYDRAULIC RESPONSE AND IODINE TRANSPORT DURING A STEAM GENERATOR TUBE RUPTURE}

\author{
R. A. Callow
}

October 1988

Idaho National Engineering Laboratory

EG\&G Idaho, Inc.

P. 0. Box 1625

Idaho Falls, Idaho 83415

\author{
Prepared for the \\ Division of Reactor Systems Safety \\ Office of Nuclear Regulatory Research \\ U. S. Nuclear Regulatory Commission \\ Washington, D. C. 20555
}

FIN No. A6328 
Recent reanalyses of the offsite dose consequences following a steam generator tube rupture have identified a possible non-conservatism in original FSAR analyses. Post-trip uncovery of the top of the steam generator $U$-tubes, in conjunction with a break near the $U$-tube top, could lead to increased iodine release due to a reduced "scrubbing" of the iodine in the primary break fluid by the steam generator secondary liquid. To evaluate this issue, analyses were performed at the Idaho National Engineering Laboratory. The RELAP5 computer code was used to conduct an analysis of the Surry plant to determine whether the post-trip steam generator secondary mixture level was sufficient to maintain continuous coverage of the $U$-tubes. The results indicated continuous coverage of the $U$-tubes. The RELAP5 result was supported by a hand calculation. Additional RELAP5 analyses were conducted to determine magnitudes of iodine release for a steam generator tube rupture. Two sensitivity studies were conducted. The amount of iodine released to the atmosphere was strongly dependent on the assumed value of the partition coefficient. The assumption of steam generator $U$-tube uncovery, on a collapsed liquid level basis, following reactor trip had a minor effect on the amount of released iodine.

FIN No. A6328 - Thermal-Hydraulic Technical Support Center 
Recent reanalyses of the offsite dose consequences following a steam generator tube rupture have identified a possible non-conservatism in original FSAR analyses. Post-trip uncovery of the top of the steam generator $U$-tubes, in conjunction with a break near the U-tube top, could lead to increased iodine release due to a reduced "scrubbing" of the iodine in the primary break fluid by the steam generator secondary liquid. The scrubbing results from a preferential retention (partitioning) of the iodine in the liquid phase, and therefore a reduced concentration in the vapor phase released through the secondary relief valves.

To evaluate this issue analyses were performed at the Idaho National Engineering Laboratory. The RELAP5 computer code was used to conduct an analysis of the Surry plant to determine whether the post-trip steam generator secondary mixture level was sufficient to maintain continuous coverage of the $U$-tubes. The results indicated continuous coverage of the U-tubes. The RELAP5 result was supported by a hand calculation.

Additional RELAP5 analyses were conducted to determine magnitudes of iodine release for a steam generator tube rupture. The amount of iodine released was calculated using a RELAP5 control system formulation based on a previous formulation developed using the TRAC computer code. The RELAP5 formulation used control variables to solve a set of mass balance equations which track iodine transport from the primary break into the secondary boiler, downcomer, and separator regions. The control system formulation allowed determination of the sensitivity of iodine release amounts to several physical parameters.

Of particular interest was the dependence of the calculated amount of release on the assumed value of the partition coefficient $(P)$. Current guidelines allow the use of a partition coefficient of 100 as a conservative value; however the value of the partition coefficient is uncertain. Therefore a sensitivity study varying the partition coefficient value was performed. For the transient scenario analyzed, (a single tube SGTR with a loss of offsite power, and requiring 30 minutes for operator actions to stop release), varying the partition coefficient from 100 to 1 resulted in an 
increase in iodine release by a factor of 42 . Assuming an initial primary coolant system iodine activity of $1.0 \mathrm{microcurie} / \mathrm{g}$, hand calculation estimates of integrated thyroid dose at the site boundary ranged from $0.002 \mathrm{rem}(P=100)$ to $0.076 \mathrm{rem}(P=1)$. For an assumed pre-accident iodine spike, dose estimates ranged from $0.036 \mathrm{rem}(P=100)$ to $1.5 \mathrm{rem}$ $(P=1)$.

An additional sensitivity study investigated the effect of assuming a period of $U$-tube uncovery on the amount of iodine release. After reactor trip, a three minute period of tube uncovery was assumed based on calculation of the time required to recover the tubes on a collapsed liquid level basis. For the case of a three minute uncovery, a $20 \%$ increase in the amount of released iodine was calculated.

The report includes discussion of the effects of modelling assumptions and operator actions on the amount of iodine release for a steam generator tube rupture. 


\section{ACKNOWLEDGMENTS}

The author wishes to thank C. D. Fletcher and C. B. Davis at INEL for assistance, and review of the work. The author also wishes to thank J. Hopenfeld, and D. Solberg of the U. S. Nuclear Regulatory Commission for their overview support of this work. 


\section{CONTENTS}

ABSTRACT $\ldots \ldots \ldots \ldots \ldots \ldots \ldots \ldots \ldots \ldots \ldots \ldots \ldots \ldots \ldots \ldots \ldots \ldots \ldots \ldots \ldots \ldots$

SUMMARY $\ldots \ldots \ldots \ldots \ldots \ldots \ldots \ldots \ldots \ldots \ldots \ldots \ldots \ldots \ldots \ldots \ldots \ldots \ldots \ldots \ldots$

ACKNOWLEDGMENTS ............................... v

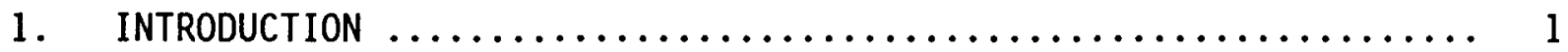

2. ANALYTICAL METHODS.AND ASSUMPTIONS ................... 4

2.1 RELAP5 Model Description...................... 4

2.2 Analysis Assumptions........................... 6

2.3 Iodine Transport Mode1...................... 7

2.3.1 Partition Coefficient $(P) \ldots \ldots \ldots \ldots \ldots \ldots \ldots \ldots \ldots \ldots$

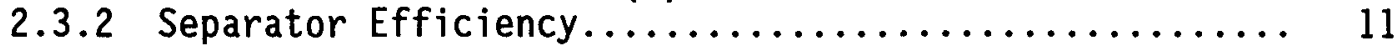

2.3.3 Mixing Fraction.......................... 12

3. RESULTS .................................. 13

3.1 RELAP5 Thermal-Hydraulic Results.................. 13

3.2 RELAP5 Iodine Transport Results.................. 30

3.2.1 Assumptions of the Iodine-Tracking Mode1.......... 30

3.2.2 Partition Coefficient Sensitivity Study............ 31

3.2.3 Mixing Fraction Sensitivity Study................ 41

3.3 Iodine Dose Estimates....................... 49

4. DISCUSSION ................................. 52

4.1 Tube Bundle Uncovery......................... 52

4.2 Modelling Deficiencies........................ 53

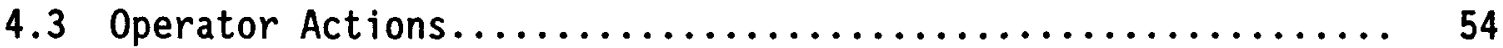

4.4 Secondary Steam Release Comparisons................. 55

4.5 Plant-to-Plant Variations...................... 56

5. CONCLUSIONS ................................. 59

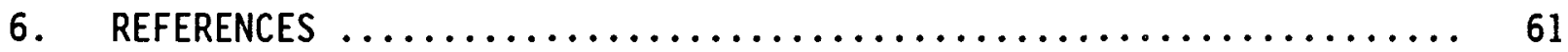

APPENDIX A - RELAP5 MODEL OF THE SURRY PWR................ 63

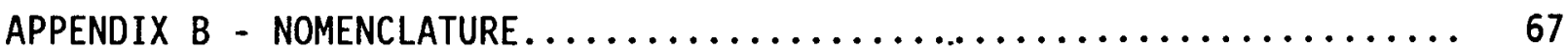


1. Schematic of mass balance on steam generator secondary heater/riser, separator/drier, and downcomer regions........... 10

2. Primary coolant break flow....................... 15

3. Primary coolant integrated break flow................. 16

4. Primary hot leg pressure........................ 18

5. Primary hot leg mass flow........................ 19

6. Primary hot leg temperature...................... 20

7. Primary cold leg pressure........................ 21

8. Secondary void fractions near the top of the boiler.......... 22

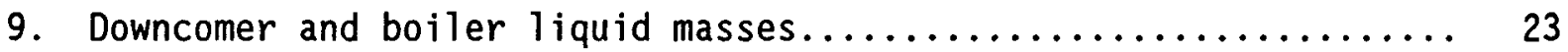

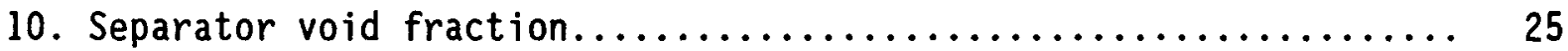

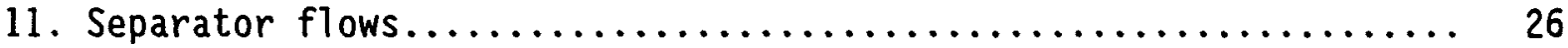

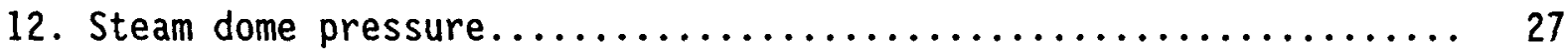

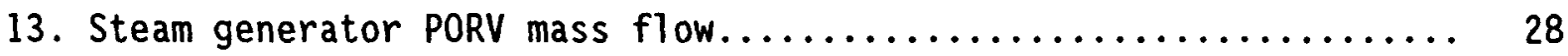

14. Boiler liquid iodine concentration as a function of partition coefficient.......................... 32

15. Boiler vapor iodine concentration as a function

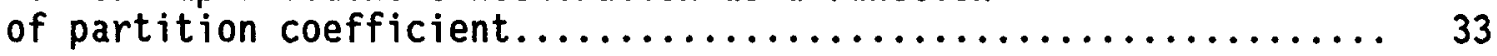

16. Separator outlet 1 iquid iodine concentration as a function

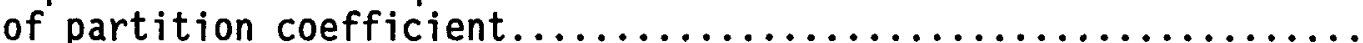

17. Separator outlet vapor iodine concentration as a function

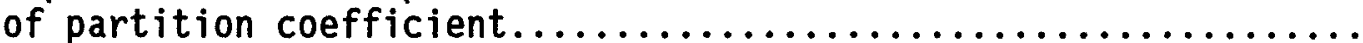

18. Downcomer iodine concentration as a function of partition coefficient.

19. Integrated iodine release to the atmosphere as a function of partition coefficient........................... 38

20. Separator outlet vapor iodine concentration for $P=1 \ldots \ldots \ldots$

21. Separator outlet vapor iodine concentration for $P=100 \ldots \ldots . \ldots 40$

22. Boiler liquid iodine concentration: mixing fraction sensitivity study 
23. Boiler vapor iodine concentration: mixing fraction

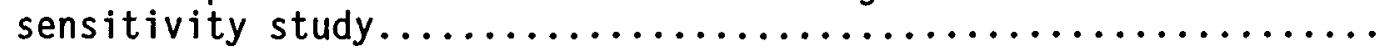

24. Separator outlet liquid iodine concentration: mixing fraction sensitivity study.

25. Separator outlet vapor iodine concentration: mixing fraction sensitivity study.

26. Downcomer iodine concentration: mixing fraction sensitivity study.

27. Integrated iodine release to the atmosphere: mixing fraction

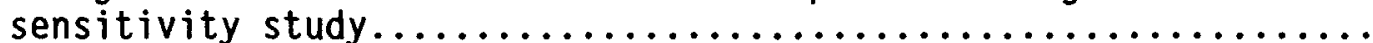

28. Steam generator schematic

\section{TABLES}

1. Initial conditions............................. 5

2. Sequence of events for the single tube SGTR............... 14

3. Atmospheric iodine release as a function of partition coefficient.. 48

4. Iodine release for different assumptions regarding tube uncovery........................... 48

5. Calculated iodine dose as a function of partition coefficient..... 51 


\section{THERMAL-HYDRAULIC RESPONSE AND IODINE TRANSPORT DURING A \\ STEAM GENERATOR TUBE RUPTURE}

\section{INTRODUCTION}

A steam generator tube rupture (SGTR) represents a breach of the primary coolant barrier between the reactor coolant system (RCS) and the steam generator secondary system. Such an accident is of particular concern because it provides a direct path to the environment for radioactive fission products in the primary fluid, via the secondary side relief valves.

An additional concern regarding SGTRs is their relative frequency. Five cases of steam generator tube ruptures were reported between 1974 and 1987.

The safety concerns regarding a steam generator tube rupture are reflected in the fact that a SGTR is designated as a design basis accident for pressurized water reactors (PWRs) and is analyzed as part of a plant's Final Safety Analysis Report (FSAR).

Following the July 15, 1987 tube rupture at the North Anna Unit 1 reactor, Virginia Electric and Power Company modified the flow resistance of the steam generator downcomers at North Anna by the addition of flow baffle plates. Subsequent to the modifications, a reanalysis of the design basis SGTR accident indicated that during the event, the water level on the secondary side could fall below the top of the U-tubes. Such an uncovery is significant because if the break itself becomes uncovered fission products in the primary coolant may have a direct path to the environment. Previous analyses which assumed that the break remained covered allowed for a "scrubbing" of the primary fluid fission products into the secondary fluid. This scrubbing effect results from preferential partitioning of the fission products into the liquid phase. The secondary liquid mass is therefore assumed to scrub the primary fluid and reduce the fission products released in the vapor phase through the steam generator relief valves. During times of break uncovery the scrubbing effect would be reduced and therefore fission product release could be higher. 
A reanalysis of the design basis accident for the Surry plant indicated the possibility of tube bundle uncovery for this plant also. In addition, a recalculation of the offsite dose consequences following a SGTR indicated doses higher than those calculated in the Surry Updated Final Safety Analysis Report (UFSAR). These higher doses were the result of the direct path for fission product release existing during times of tube bundle uncovery.

Based on the information from the reanalyses on the North Anna and Surry plants, the United States Nuclear Regulatory Commision (NRC) issued an information notice (Number 88-31 on May 25, 1988) to all holders of operating 1 icenses or construction permits for Westinghouse- and Combustion Engineering-designed nuclear power reactors. The information notice alerted the holders to the possible non-conservatism in the analysis of offsite dose consequences for a SGTR.

The work presented in this report addresses several issues related to the tube bundle uncovery and fission product release during a SGTR. Two main questions are addressed: (1) Does the top of the tube bundle uncover following reactor trip? and (2) What are important considerations in estimating the magnitude of iodine release during a steam generator tube rupture?

In order to assess whether the tubes are likely to uncover following reactor trip, a system calculation for the Surry plant was performed using the RELAP5 safety analysis code. Estimation of mixture level in the secondary ststem can be made from inspection of void distribution obtained in the RELAP5 calculation. The hand calculations performed by Virginia Electric and Power Company (VEPCO) which indicated the tube bundle would uncover assumed that the secondary liquid was completely collapsed with no voids beneath the water surface. This is a conservative assumption because in fact the heat transfer from primary to secondary will result in a mixture level which is higher than the collapsed level. The mixture level may cover the tubes during times when the collapsed level does not. In contrast to the conservative VEPCO hand calculation, the RELAP5 calculation, by accounting for void distribution in the secondary, allows assessment of 
whether the mixture level is sufficient to cover the tubes.

The second issue addressed in this report is iodine transport from the primary to the secondary fluid and the magnitude of iodine release. The iodine transport is modelled using a mass balance formulation ${ }^{1}$ and is implemented in a RELAP5 control system which is based on a TRAC formulation previously described. ${ }^{2}$ The magnitude of iodine release will be dependent on the specific SGTR scenario which is modelled. In this report an attempt was made to embody the Surry UFSAR assumptions.

A key motivation for the analyses presented here was the determination of relative amounts of iodine release for different assumptions regarding iodine partitioning and the mixing of primary break fluid with the secondary fluid. For this reason several important sensitivity analyses were performed. A sensitivity study of iodine release relative to the assumed value of the partition coefficient was conducted. An additional sensitivity study assessed the effect of reduced mixing of the break fluid with the secondary fluid for a period of time in which the tubes were assumed to be uncovered.

The remainder of this report is organized as follows. Section 2 presents the analytical methods and assumptions. The results of the analyses are presented in Section 3. A discussion of the results is given in Section 4, followed by a summary of conclusions in Section 5 . 


\section{ANALYTICAL METHODS AND ASSUMPTIONS}

This section presents the analytical methods and assumptions used in the RELAP5 analysis of the steam generator tube rupture. Section 2.1 presents a brief desciption of the Surry plant and the RELAP5 representation of the plant. A more detailed desciption of the RELAP5 model is provided in Appendix A. The assumptions used in the analysis are discussed in Section 2.2. A description of the iodine transport model is presented in Section 2.3 .

\subsection{RELAP5 Model Description}

The Surry plant is a Westinghouse-designed pressurized water reactor with three coolant loops and a rated core thermal power of $2441 \mathrm{MW}$. The plant uses Westinghouse Series 51 steam generators.

The RELAP5 model consists of components for the reactor vessel; three coolant loops, each of which contains a U-tube steam generator, a reactor coolant pump, and associated piping; the pressurizer; and the secondary sides of the steam generators. A more complete description of the Surry model is found in Appendix A.

Prior to performing the transient calculations, a steady-state calculation was conducted to verify that calculated initial conditions were representative of the actual plant operating conditions. Table 1 shows a comparison between the calculated initial conditions and the operating conditions found in the Surry UFSAR. ${ }^{3}$ The RELAP5-calculated initial conditions are in good agreement with the UFSAR values.

The results presented in this report are derived from both a full system calculation and separate effects calculations. In the full system calculation, the response of the entire plant to the steam generator tube rupture was obtained. The iodine transport separate effects calculations were performed using a model of the affected steam generator alone. Boundary conditions for this separate effects steam generator model were provided by the results of the full system calculation. The boundary 
TABLE 1. INITIAL CONDITIONS

\begin{tabular}{|c|c|c|}
\hline Parameter & RELAP5 & Desired \\
\hline Total loop flow $(1 \mathrm{bm} / \mathrm{s})$ & 27972. & 27972 . \\
\hline Core inlet temperature $\left({ }^{\circ} \mathrm{F}\right)$ & 543. & 543. \\
\hline Core exit temperature $\left({ }^{0} \mathrm{~F}\right)$ & 606. & 608. \\
\hline Steam flow per $S G(1 \mathrm{bm} / \mathrm{hr})$ & $3.53 \mathrm{E} 6$ & $3.51 \mathrm{E} 6$ \\
\hline Steam temperature $\left({ }^{0} \mathrm{~F}\right)$ & 521. & 516. \\
\hline Steam pressure (psia) & 827 . & 785. \\
\hline Feedwater temperature $\left({ }^{\circ} \mathrm{F}\right)$ & 430. & 430 \\
\hline
\end{tabular}


conditions specified for the separate effects calculation were hot leg pressure, hot leg temperature, hot leg mass flow rate, and cold leg pressure.

\subsection{Analysis Assumptions}

The analysis was performed for the rupture of a single steam generator tube. The rupture was assumed to occur at the top of the tube bundle.

For the analysis of the SGTR transient an attempt was made to use modelling assumptions used in the Surry UFSAR design basis accident. There were however several deviations from the standard assumptions. The following is a list of assumptions and justification for them. A discussion of the calculation assumption and their effects on iodine release is provided in Section 4.

1) Charging flow was not modelled. Prior to reactor trip, charging flow would increase in order to maintain pressurizer level during primary system depressurization. In this analysis charging flow was not modelled due to lack of information.

2) Pressurizer heaters were not modelled. The heaters would act to maintain primary pressure during the initial depressurization. Information regarding these heaters was not available.

3) A loss of offsite power occurred coincident with reactor trip. This assumption was derived from the UFSAR. The loss of offsite power caused a loss of condenser. As a result steam release from the secondary was through the steam generator PORVs and/or SRVs directly to the environment. The loss of offsite power also resulted in a trip of the reactor coolant pumps as well as the termination of main feedwater.

4) Auxiliary feedwater at $50 \%$ capacity was initiated $60 \mathrm{~s}$ after reactor trip. This corresponded to the steam-driven auxiliary feedwater. This assumption was derived from the UFSAR. 
5) Flow from one safety injection (SI) pump was initiated $60 \mathrm{~s}$ after reactor trip. This assumption was derived from the UFSAR.

6) Steam generator PORVs were assumed to be operable. Westinghouse Emergency Response Guidelines ${ }^{4}$ indicate that in the case of loss of offsite power, the steam generator PORVs should be powered by the diesel generators. In this calculation the PORVs were modelled as modulating valves based on control information from the $H$. B. Robinson $\mathrm{plant}$ model ${ }^{5}$.

7) Prior to reactor trip the steam generator mass in the affected steam generator was assumed to be maintained constant. The inflow of primary fluid from the tube rupture coupled with the flow of main feedwater would cause an increase in level (and mass) of the steam generator. An assumption was made that a control system would automatically reduce main feedwater flow in order to maintain constant level. For this calculation a control system was implemented to maintain constant liquid mass in the steam generator prior to reactor trip. Although this control system was not based on plant information, it is likely that it produced a result similar to the actual plant control system.

8) Operator actions were not assumed. As will be seen, the most significant result of this assumption was a high liquid level in the affected steam generator.

9) The transient was terminated in 30 minutes. This assumption was based on the UFSAR. The termination of the transient in 30 minutes would likely results from operator actions. A discussion of the role of operator actions during an SGTR is provided in Section 4.

\subsection{Iodine Transport Model}

The iodine transport model used in this analysis is based on the formulation developed in Reference 1. An earlier implementation of the basic formulation in terms of a TRAC code control system is described in Reference 2. For this work the development of the RELAP5 control system formulation was based directly on the earlier TRAC implementation. 
In this section the basic formulation of the mass balance equations will be described. The complete description of the mass balance formulation and the solution method is found in Reference 2. The following description is derived directly from the full description presented in the reference.

The method used is one for determining the transport of a radioactive component (in this case, iodine) from the primary system into and throughout the secondary system during a steam generator tube rupture transient. The method utilizes a set of mass balance equations for the boiler, the downcomer, and the separator regions of the steam generator. The mass balance equations are solved using sets of RELAP5 control variables with required thermal-hydraulic parameters obtained directly from the RELAP5 code. Solution of the mass balance equations for the three regions described above results in liquid and vapor concentrations for each of the regions. Knowledge of the concentrations, coupled with liquid and vapor flow rates leaving the secondary system allows determination of iodine release to the environment.

Figure 1 illustrates the manner in which the steam generator secondary is divided for formulation of the iodine transport model. Included in the figure are the various flow and deposition terms that are used to obtain a mass balance for the radioactivity component in each region. The mass balance equations for the three regions are as follows, with the quantities used in the equation being defined in Appendix B. In the boiler region:

$$
\frac{d}{d t}\left(M_{H} c_{H}\right)=\dot{m}_{p} c_{p}+\dot{m}_{D} c_{D}-\dot{m}_{S} c_{S}-s_{H}
$$

For the separator/drier region:

$$
\frac{d}{d t}\left(M_{S} c_{S}\right)=\dot{m}_{S} c_{S}-\dot{m}_{E} c_{E}-\dot{m}_{0} c_{0}-s_{S}=0
$$

For the downcomer:

$$
\frac{d}{d t}\left(M_{D} c_{D}\right)=\dot{m}_{E} c_{E}-\dot{m}_{F} c_{F}-\dot{m}_{D} c_{D}-s_{D}
$$


Note that the assumption is made that there is no mass storage in the separator.

The development and solution of the equations relies on the definition of several parameters representing physical processes involved in the transport of the radioactive component. These parameters are defined as follows:

Fraction of primary liquid reaching the separators without prior mixing:

$$
\begin{aligned}
& \text { mass flow of primary liquid } \\
& \beta=\text { entering separator without mixing } \\
& \text { mass flow of primary liquid } \\
& \text { entering secondary side }
\end{aligned}
$$

Overall separator efficiency for liquid removal:

$$
\eta=\frac{\text { mass flow of liquid entering }}{\text { mass flow of liquid at inlet }} \begin{aligned}
& \dot{m}_{E, 1} \\
& \text { to separator }
\end{aligned}=\dot{m}_{S, 1}
$$

Partition of radioactive component between liquid and vapor:

$$
P=\frac{\text { per unit volume of liquid }}{\text { mass of radioactive component }}=\frac{1 \mathrm{c} \rho}{\mathrm{c}_{\mathrm{g}} \rho \mathrm{g}}
$$

The following subsections give a further description of the above parameters and the significance of each of them for the analysis of a steam generator tube rupture. 


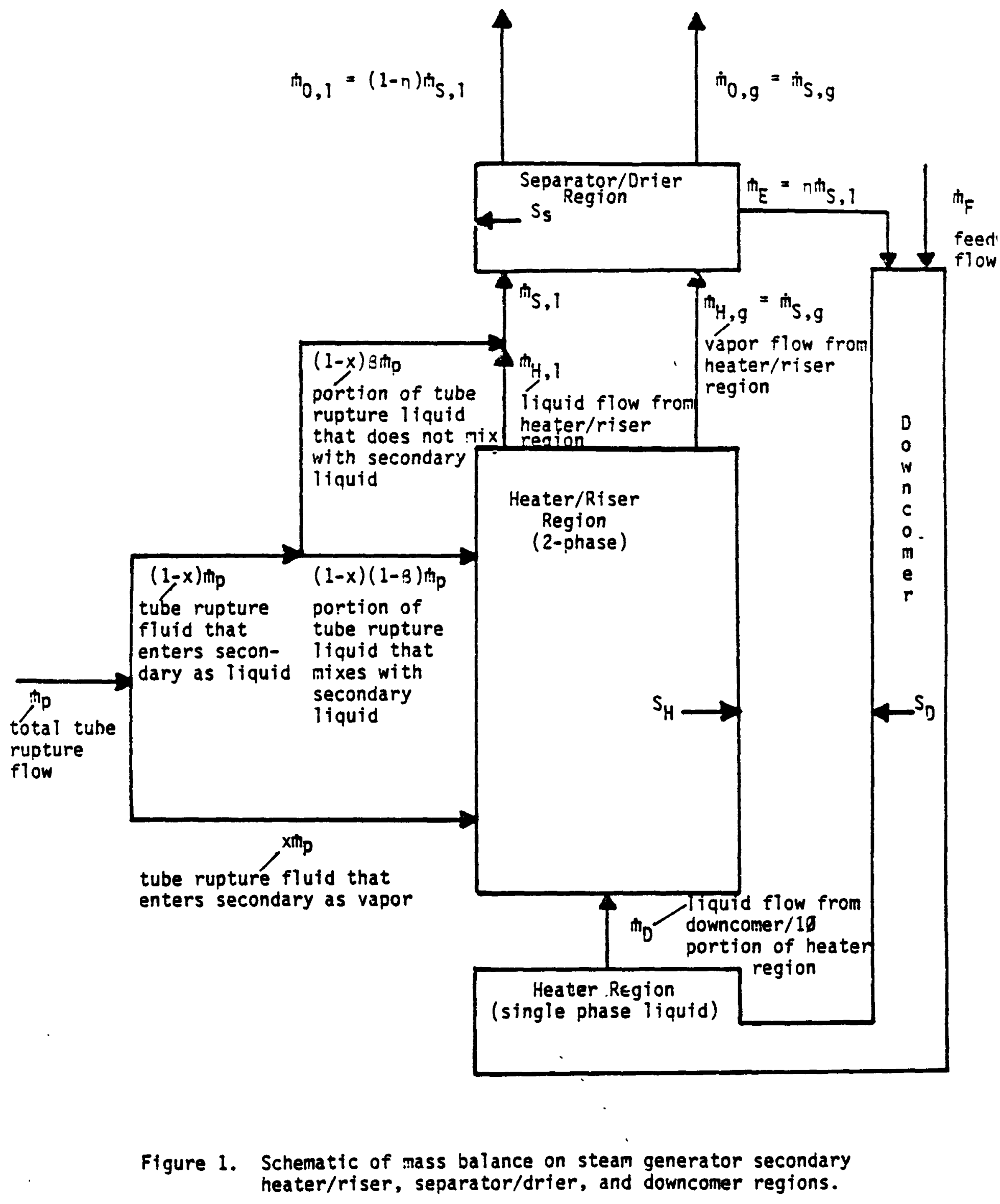




\subsubsection{Partition Coefficient (P)}

The partition coefficient is a measure of the relative distribution of the radioactive component (iodine) between the liquid and vapor phases. The definition of the partition coefficient given above is on a volumetric basis; it is the ratio of the mass of iodine per volume of liquid to the mass of iodine per volume of vapor. The partition coefficient is also defined on a mass basis, the mass basis definition is the one commonly used in FSARs. The conversion between the two definitions is as follows:

$$
P_{\text {mass basis }}=\left(\mathrm{P}_{\text {volume basis }}\right)\left(\rho_{\mathrm{g}} / \rho_{1}\right)
$$

For the analyses described in this report the density ratio was assumed to be constant at 0.048 . This corresponds to a saturated secondary system at a temperature of $544^{\circ} \mathrm{F}$.

The partition coefficient can be dependent on a number of parameters such as $\mathrm{pH}$, temperature, and concentration. Also, the partition coefficient measured at equilibrium conditions may not apply during a SGTR transient which may proceed on a faster time scale than that required for partitioning equilibrium to be reached.

The partition coefficient is a physical parameter whose value is independent of assumptions regarding tube bundle uncovery during a SGTR. A tube bundle uncovery should not affect the relative partitioning; instead the relative mixing of primary break fluid with secondary fluid should be affected. In the present analysis these two effects are separated. The partitioning is described by the partition coefficient and the relative mixing is described by the mixing fraction.

\subsubsection{Separator Efficiency}

The iodine transport model provides for the specification of a value for separator efficiency to allow determination of the effect of degraded separator performance on iodine release. In the present analyses this 
capability was not used and the separator efficiency used in the iodine-tracking control system was determined by the RELAP5 thermal-hydraulic calculation.

\subsubsection{Mixing Fraction}

The mixing fraction is a measure of how well the primary fluid from the rupture mixes with the secondary fluid. It is expected that if the break is covered with secondary fluid the mixing will be better than if the break is uncovered. Data from the MB-2 experimental facility indicated very high mixing between the primary and secondary fluid. ${ }^{6}$ This occurred even in the case of an uncovered break. 


\section{RESULTS}

This section presents the thermal-hydraulic results for the SGTR with a loss of offsite power. The results from the RELAP5 full system calculation are presented in Section 3.1. The results of the separate effects iodine transport studies are presented in Section 3.2. The results of a hand calculation estimate of iodine doses is presented in Section 3.3.

\subsection{RELAP5 Thermal-Hydraulic Results}

The thermal-hydraulic results presented in this section represent values obtained from the separate effects runs. As indicated previously, boundary conditions for the separate effects runs were obtained from the RELAP5 full system calculation. Prior to the overfill of the steam generator the thermal hydraulic results observed in the separate effcts runs were virtually identical to those of the full system calculation. After steam generator overfill ( $t>1200 \mathrm{~s}$ ) there were slight differences between the two cases. These differences were attributed to small approximation errors in the specification of boundary conditions for the separate effects calculations.

Table 2 lists the sequence of events for the SGTR with a loss of offsite power occurring at the time of reactor trip.

The initiation of the tube rupture resulted in the flow of primary coolant into the steam generator secondary. Figure 2 shows the break flow and Figure 3 indicates the integrated break flow. The loss of primary fluid resulted in depressurization of the primary system as seen in Figure 4 . The calculated depressurization rate was likely higher than the actual plant rate because charging flow and pressurizer heaters were not modelled. Both charging flow and heaters would act to retard the depressurization. At $483 \mathrm{~s}$ the reactor tripped due to low pressurizer pressure $(P<1890$ psia). The reactor trip caused a rapid cooldown and decrease in the specific volume of the liquid in the reactor coolant system (RCS) resulting in a rapid depressurization. At $714 \mathrm{~s}$ a safety injection (SI) signal was generated as the primary system pressure dropped below 1730 psia. One SI pump was 
TABLE 2. SEQUENCE OF EVENTS FOR THE SINGLE TUBE SGTR

Time

(s)

Event

0.0

SGTR occurred

483

Reactor trip; turbine trip; loss of offsite power

498

Secondary pressure reaches 1050 psia: steam relief through steam generator PORVs

543

$50 \%$ auxiliary feedwater initiated

714

SI signal; flow initiated from one SI pump

970

Affected SG PORV modulates closed

1000

Affected $S G$ separator begins filling with liquid

1315

Affected SG PORV modulates open

1800

Calculation terminated 


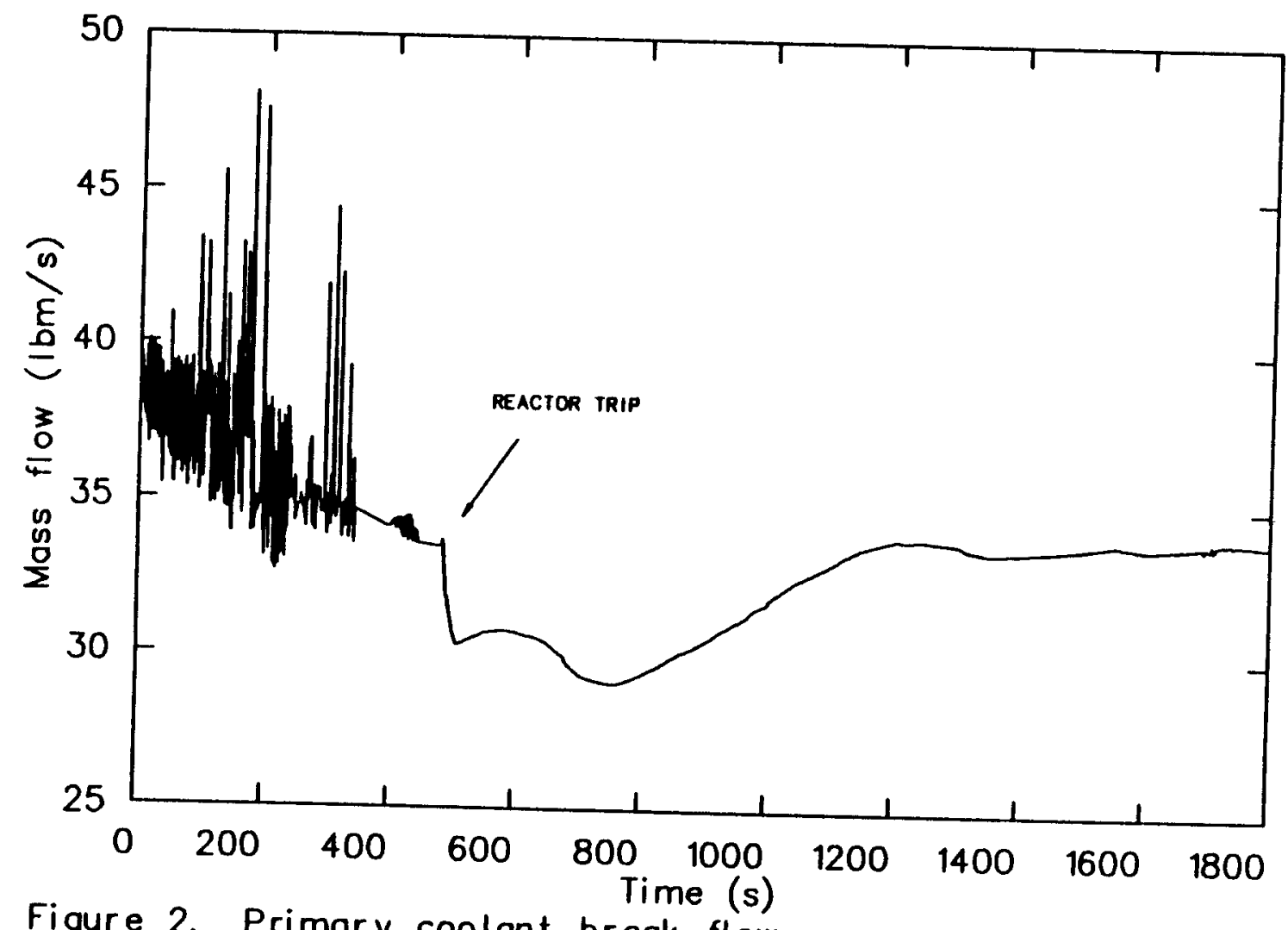

Figure 2. Primary coolant break flow. 


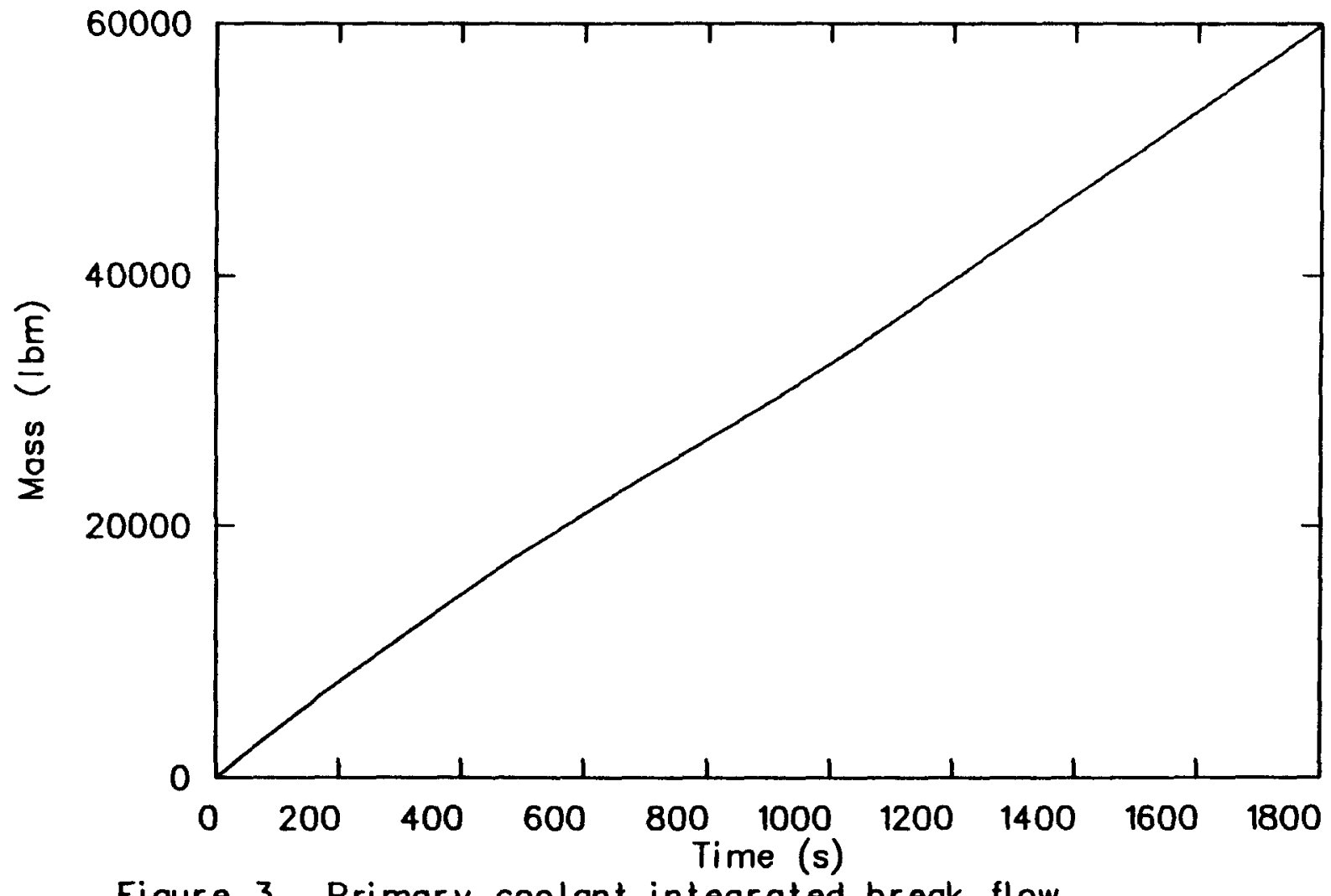

Figure 3. Primary coolant integrated break flow. 
assumed to operate and resulted in a slight repressurization of the primary after $800 \mathrm{~s}$ as shown in Figure 4.

Due to the loss of offsite power the reactor coolant pumps (RCPs) tripped at the time of the reactor trip. The decrease in loop flow is shown in Figure 5. The decrease in loop flow coupled with the decline of core power explains the hot leg temperature response observed in Figure 6 . Immediately after reactor trip the decline in core power was more rapid than the corresponding decline in loop flow rate and the hot leg temperature dropped rapidly. After about $500 \mathrm{~s}$ however the hot leg fluid temperature increased as the core decay heat was sufficient to heat up the reduced natural circulation flow. After $700 \mathrm{~s}$ the continued removal of primary energy in the steam generators and the addition of subcooled SI flow caused gradual decline of primary temperatures.

Figure 7 shows the cold leg pressure response which is similar to the pressure response of the hot leg (Figure 4). Figures 4, 5, 6, and 7 depict the boundary conditions from the full system calculation which were used as input for the separate effects calculation.

The remainder of this section describes the behavior of the affected steam generator. Prior to reactor trip the steam generator remained at steady-state operating conditions. As mentioned previously, liquid mass in the steam generator was maintained constant by reducing the main feedwater flow by an amount equal to inflow from the break. After reactor trip the rapid reduction in the amount of heat transfer from the primary to the secondary resulted in a reduction of secondary voids. Figure 8 shows the reduction in void fraction in volumes 476-8 (top of boiler), and 477-1 (above top of $U$-tubes). The low void in these two volumes subsequent to reactor trip indicates that the RELAP5 calculation showed that the top of the $U$-tubes remain covered by the mixture level.

The reduction in boiler void fractions after reactor trip was accompanied by a significant redistribution of mass from the downcomer to the boiler as indicated in Figure 9. The redistribution of mass can be explained in terms of the pre- and post-trip pressure profiles. Both before and after trip the pressure drop through the downcomer due to elevation and 


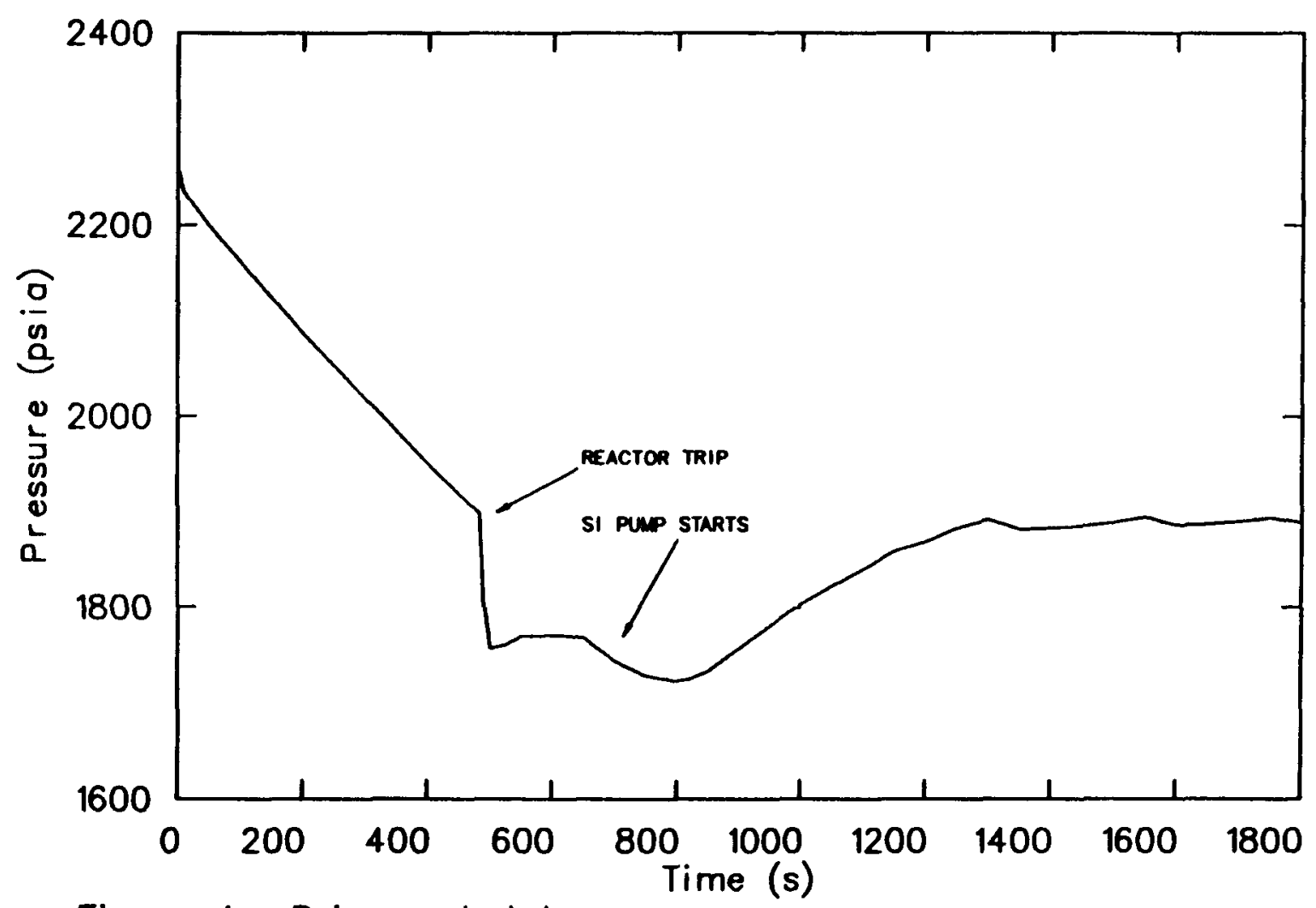

Figure 4. Primory hot leg pressure. 


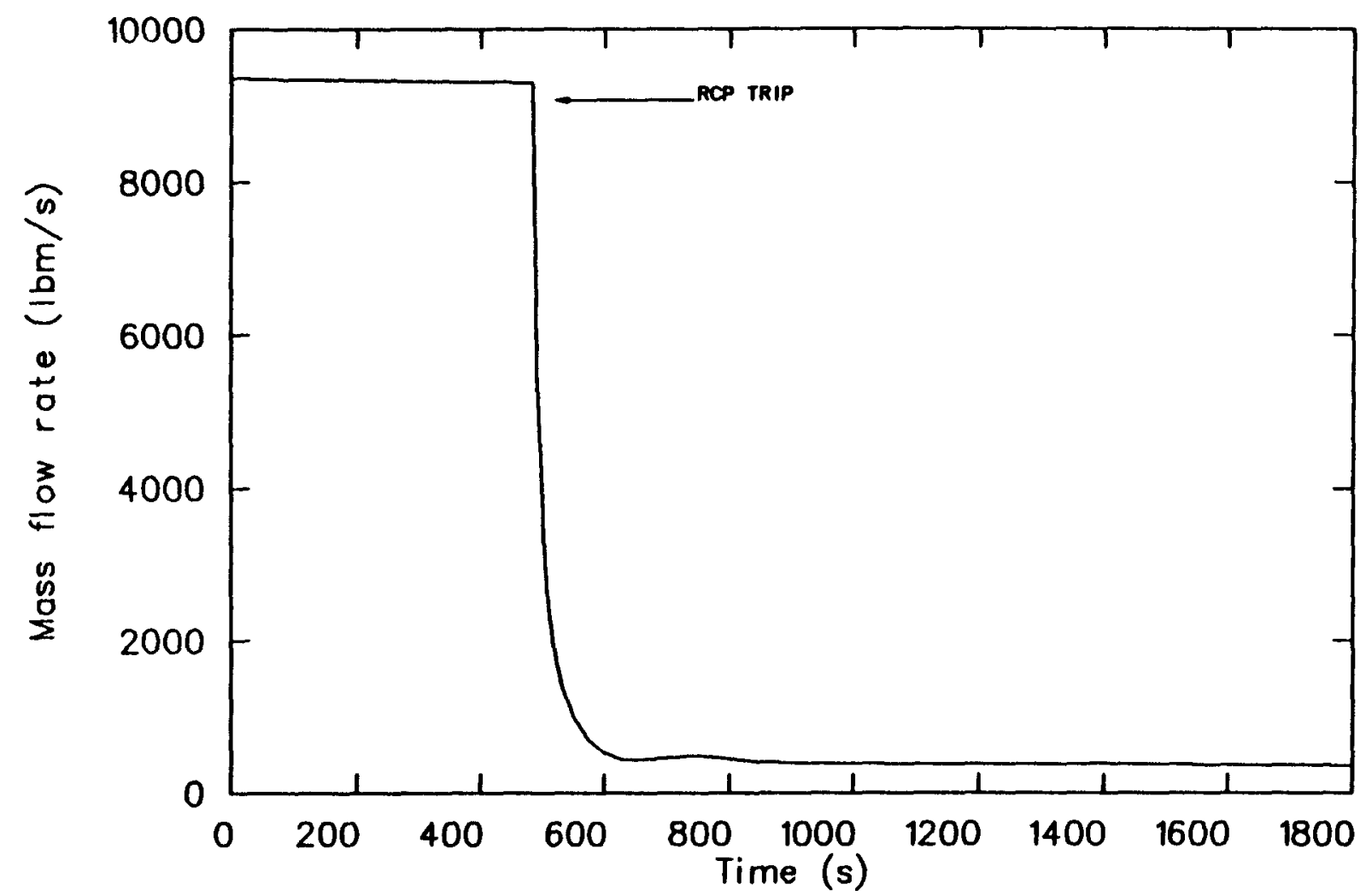

Figure 5. Primary hot leg moss flow. 
ก

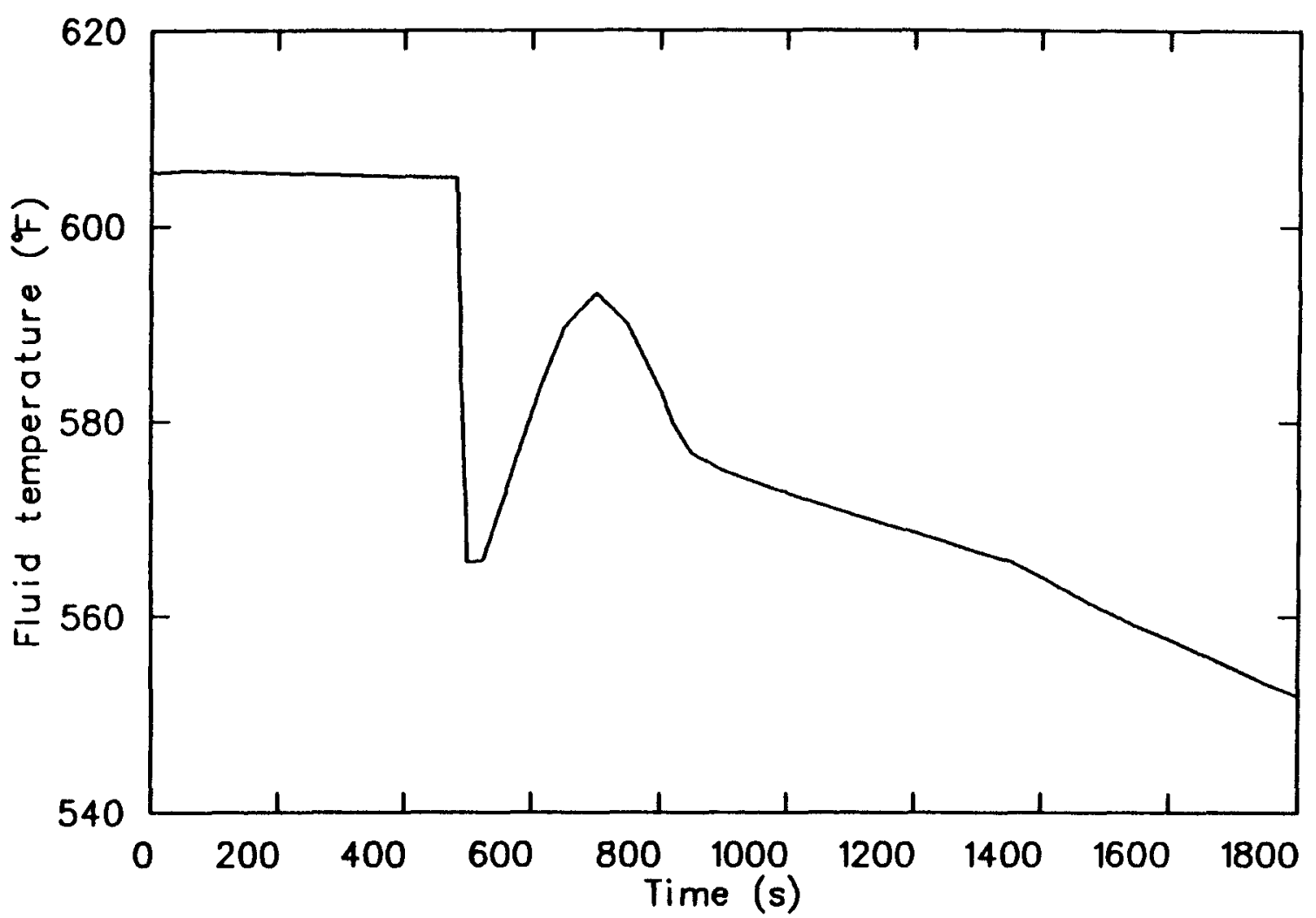

Figure 6. Primary hot leg temperature. 


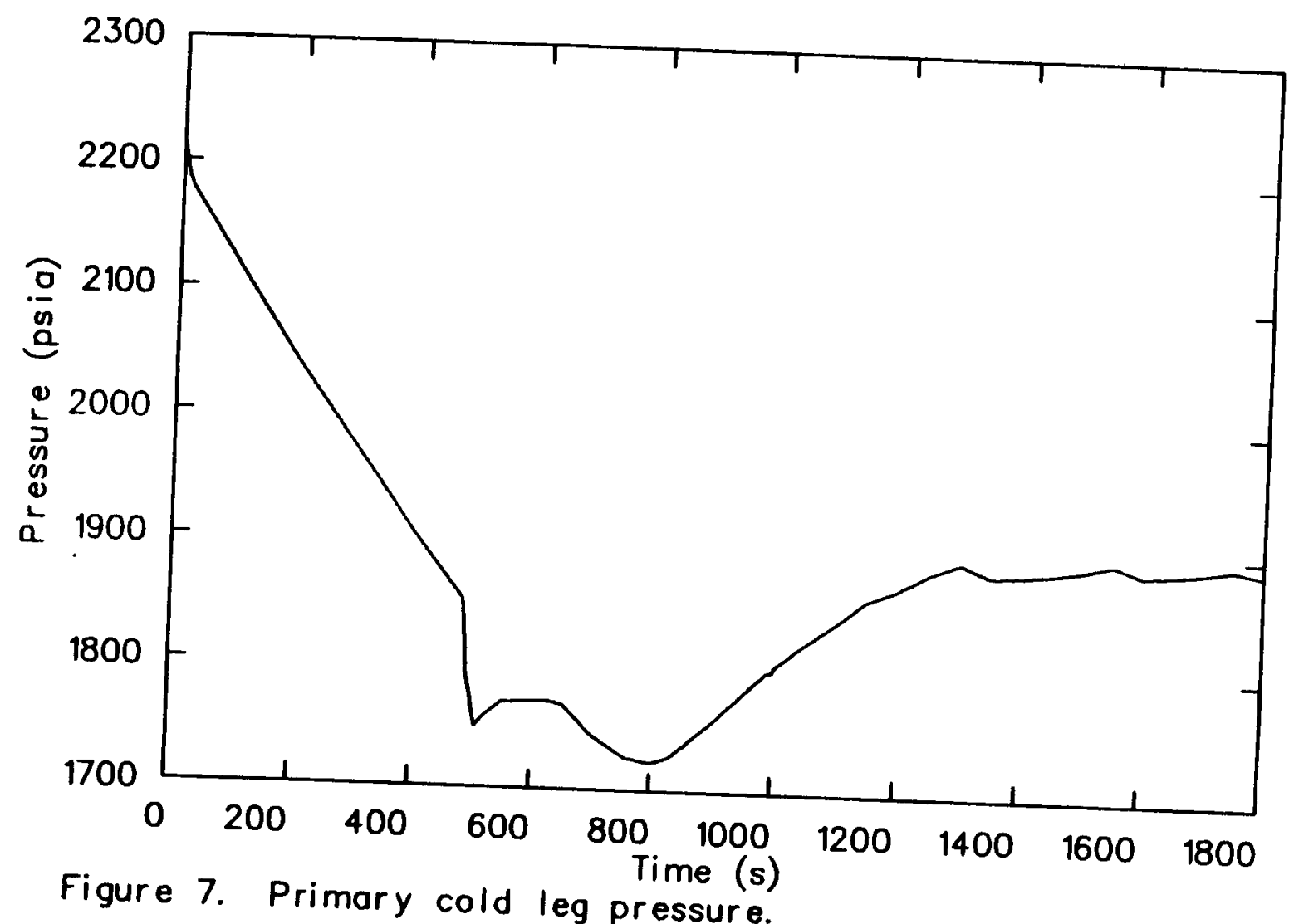




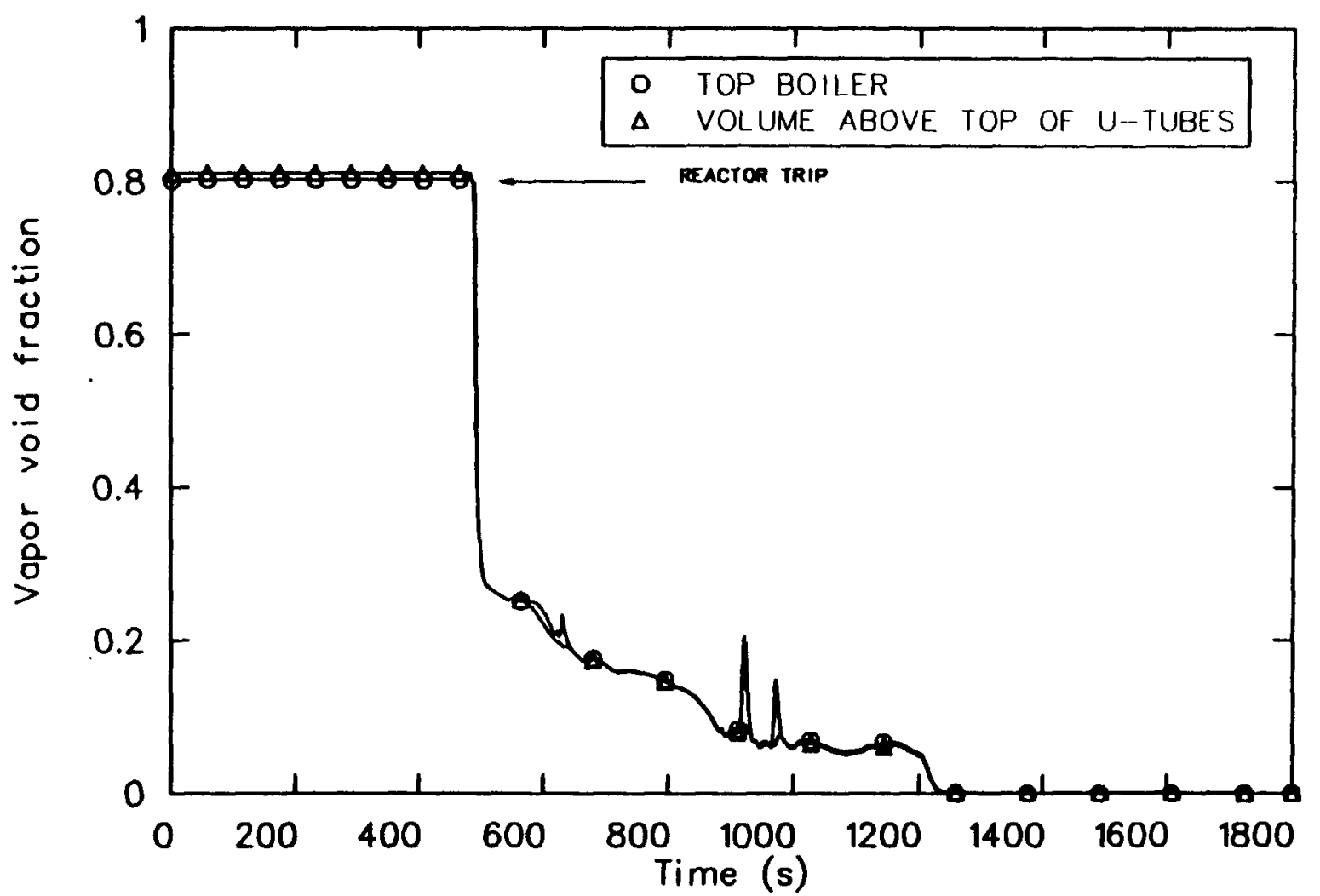

Figure 8. Secondary void fractions near top of the boiler. 


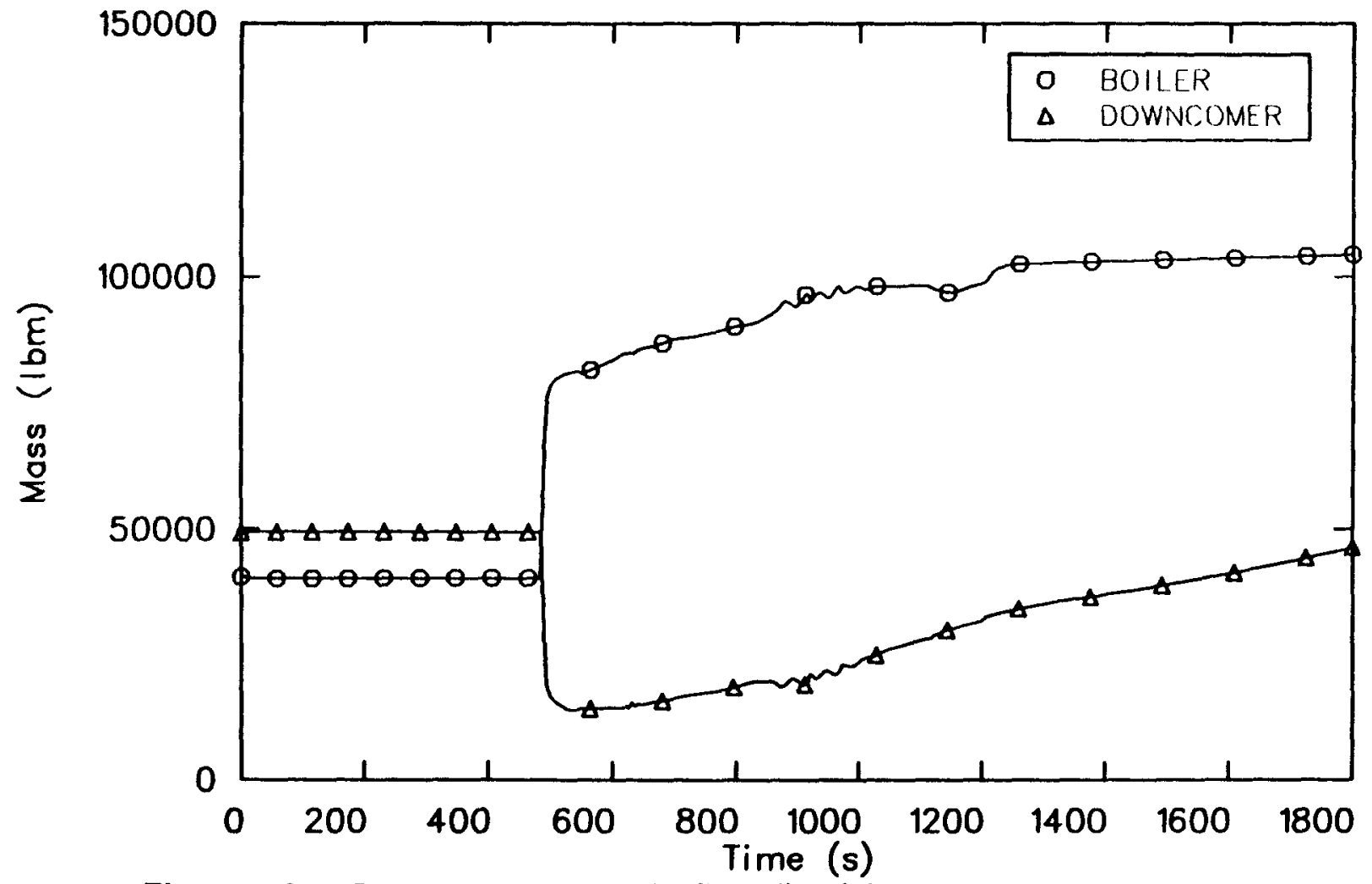

Figure 9. Downcomer and boiler liquid mosses. 
flow contributions was balanced by the pressure drop in the boiler due to elevation and flow contributions. Prior to reactor trip the downcomer was liquid-full whereas the boiler was significantly voided. The smaller elevation pressure drop associated with the larger voids was compensated for by the larger pressure drop associated with the two-phase flow. After reactor trip the boiler pressure drop due to two-phase flow was significantly reduced. Equilibration of pressure resulted in a drop of liquid level in the downcomer as mass was transferred to the boiler. At the same time, according to the RELAP5 results, the continuing primary to secondary heat transfer was sufficient to maintain a mixture level above the top of the tubes. The initiation of auxiliary feedwater at $543 \mathrm{~s}$ provided additional mass which increased secondary level.

The continuation of auxiliary feedwater eventually caused high level in the affected steam generator, as seen in Figure 10 which shows the filling of the separator with liquid after about $1000 \mathrm{~s}$. Because of the assumption that auxiliary feedwater was not throttled, both the boiler and the separator eventually became liquid-full.

Separator mass flows are shown in Figure 11. The closing of the turbine stop valves at reactor trip resulted in the cessation of steam flow. Recirculation flow was also significantly reduced. The auxiliary feedwater flow which was initiated at $543 \mathrm{~s}$ eventually resulted in the reestablishment of recirculation flow.

The steam generator pressure response is shown in Figure 12. The steam generator PORVs were modulated using a control system to maintain secondary pressure at 1050 psia. A small modelling error should be noted. The steam generator PORVs were assumed operable even with a loss of offsite power because operating guidelines indicated that they would be powered by diesel generators. However one or more minutes would be required in order to start up the diesel generators. Therefore steam release immediately after reactor trip would probably occur through the safety relief valves. This release would be at a higher pressure (1184 psia).

Figure 13 indicates the mass flow rates through the steam generator PORV. The flow between 500 and $1000 \mathrm{~s}$ resulted from boiling in the 


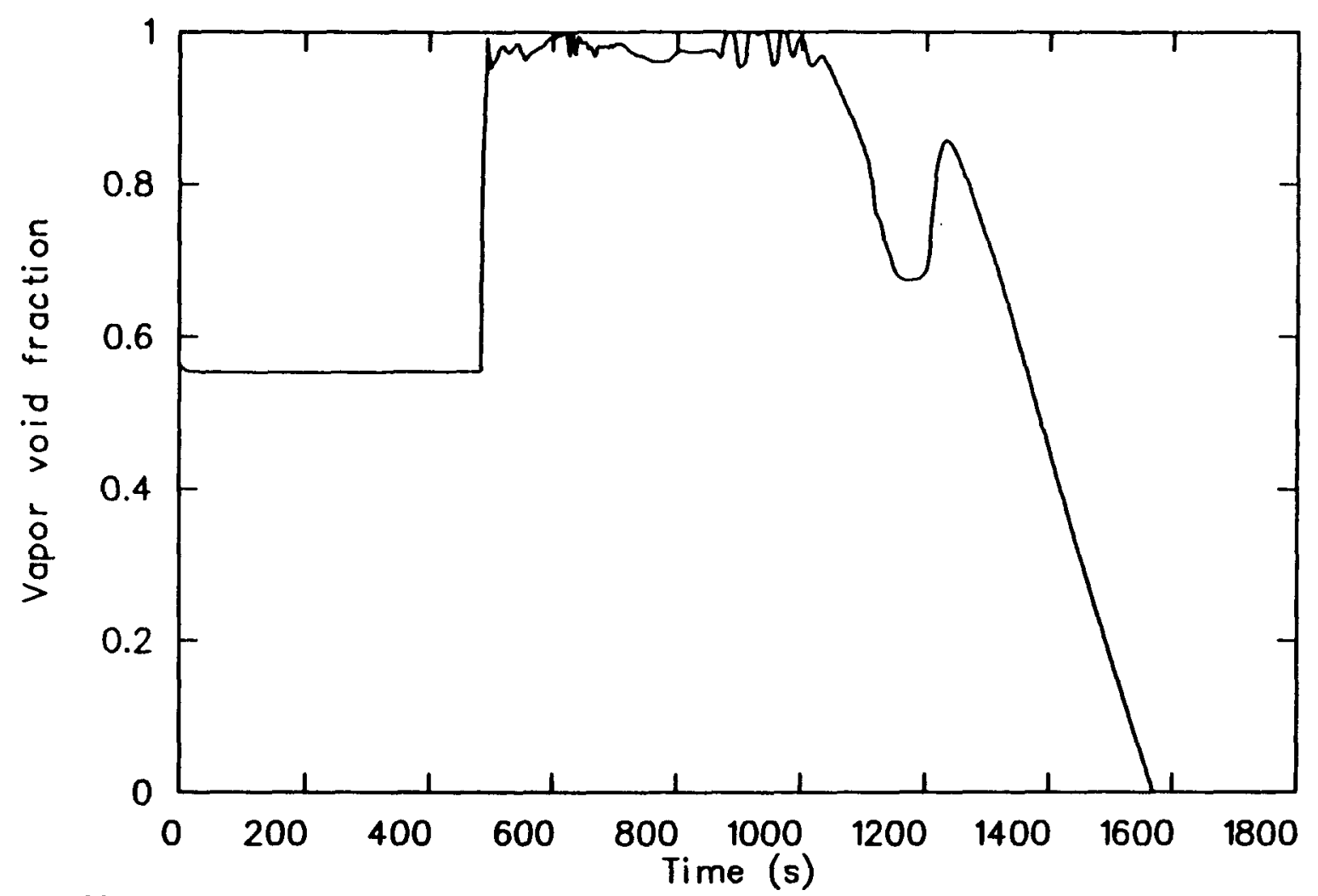

Figure 10. Separator void fraction. 


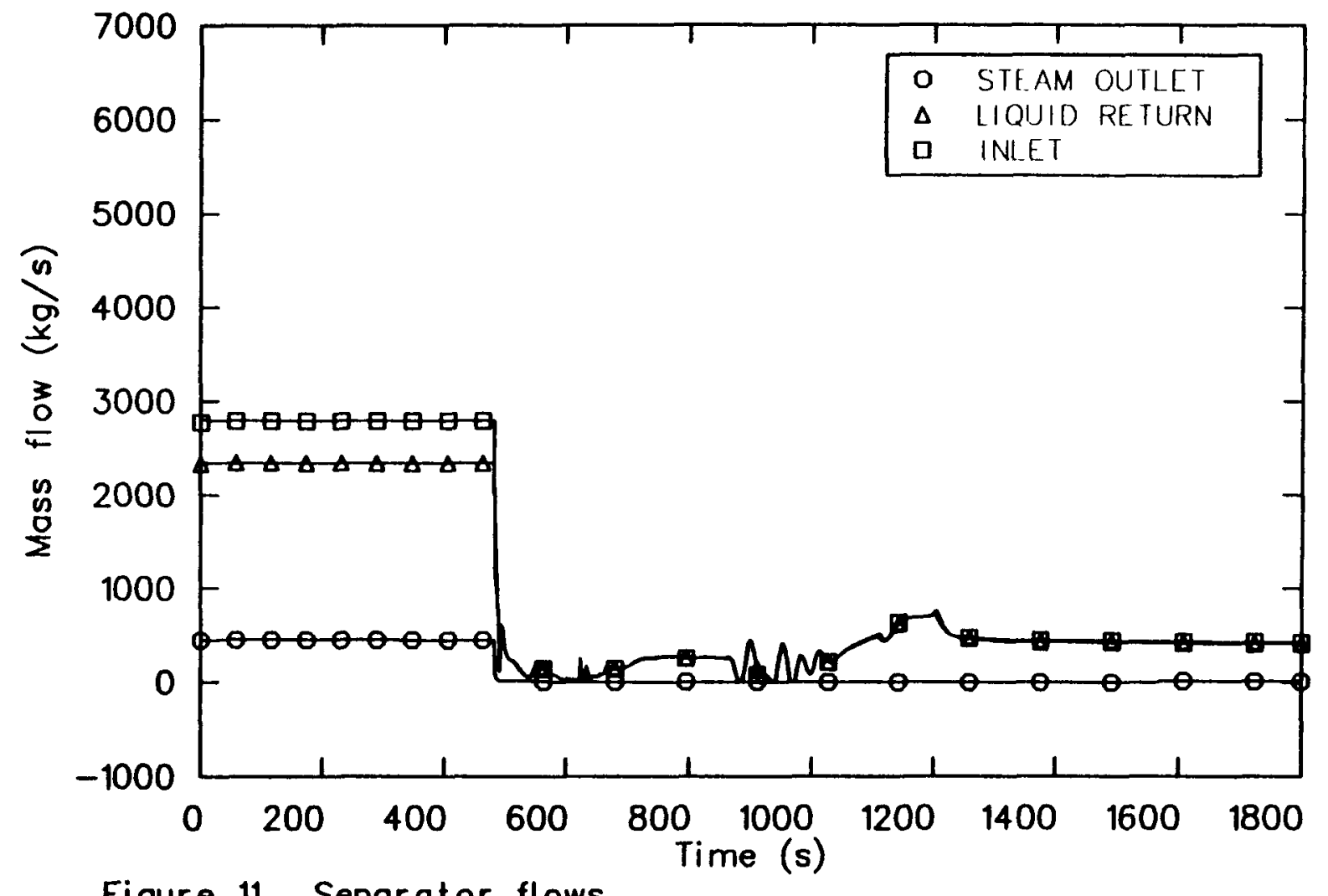

Figure 11. Separator flows. 


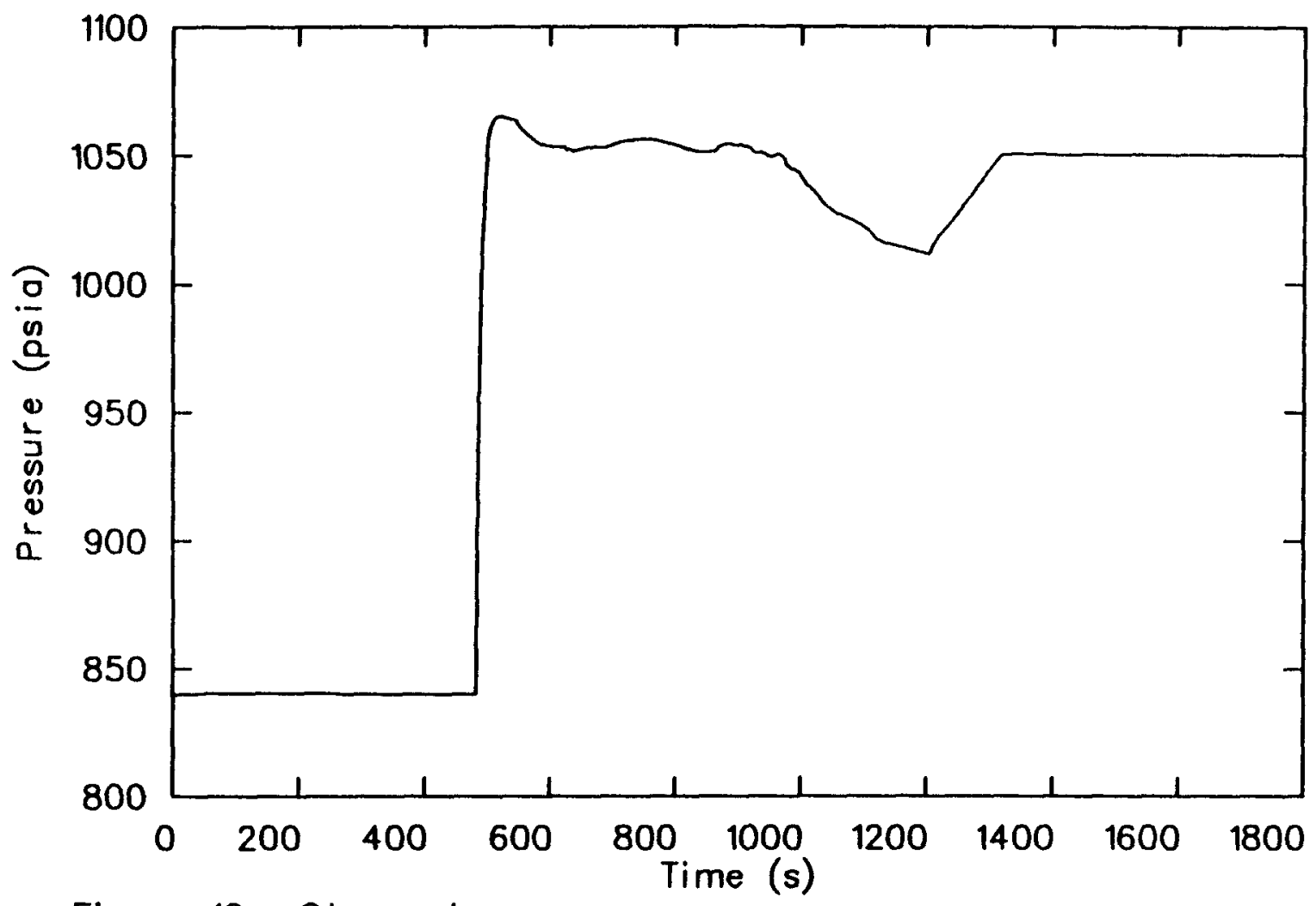

Figure 12. Steam dome pressure. 


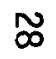

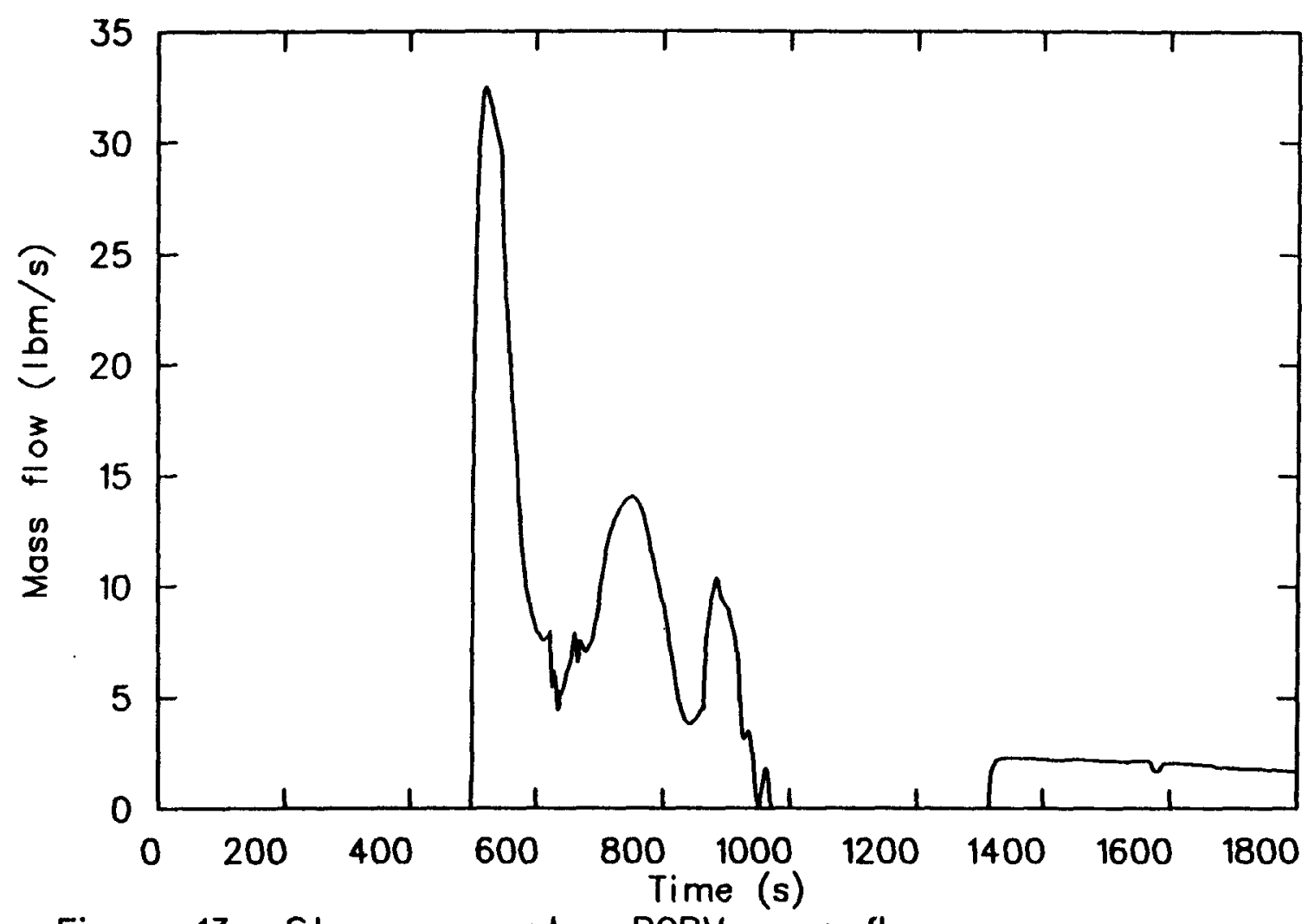

Figure 13. Steam generator PORV mass flow. 
secondary as core decay heat continued to be removed from the primary. However the flow from $1300 \mathrm{~s}$ to $1800 \mathrm{~s}$ was a result of the steam generator overfill. At $1300 \mathrm{~s}$ the boiler liquid was subcooled and vapor generation in the steam generator was negligible. However liquid mass continued to be added via the break and auxiliary feedwater. The volume associated with this mass caused pressurization of the steam bubble at the top of the steam generator and a displacement of steam out the PORV.

If the operators were assumed to throttle auxiliary feedwater in order to prevent high steam generator level, the steam release associated with the volume displacement after $1300 \mathrm{~s}$ would likely not occur. However throttling the auxiliary feedwater would reduce a source of secondary subcooling for absorbing core decay heat and could result in increased boiling and steam release at earlier times. A further discussion of this issue is provided later.

The calculation was terminated at $1800 \mathrm{~s}$ based on the standard FSAR assumption that within 30 minutes the operators will take action to isolate the affected steam generator and terminate steam release from it. A discussion of operator actions and their effect during a steam generator tube rupture is provided in Section 4 .

A brief overview of the calculated thermal-hydraulic response for the single tube SGTR follows. The tube rupture caused a depressurization of the primary system with a resultant reactor trip at $483 \mathrm{~s}$. The loss of offsite power coincident with reactor trip caused closure of the turbine stop valves which in turn resulted in an increase in secondary pressure. Steam release to the environment through the steam generator PORVs occurred from approximately $500 \mathrm{~s}$ to $1000 \mathrm{~s}$ as a result of vapor generation due to primary-to-secondary heat transfer. Continued filling of the affected steam generator, by auxiliary feedwater, resulted in additional steam release from approximately $1300 \mathrm{~s}$ to $1800 \mathrm{~s}$. This release resulted from volumetric displacement of the steam bubble at the top of the steam generator. The calculation was terminated at $1800 \mathrm{~s}$. 


\subsection{RELAP5 Iodine Transport Results}

Iodine transport in the secondary system is dependent on several factors. First since the iodine is being transported by the secondary liquid and vapor flows, the secondary thermal hydraulic response, as described above, provides the driving force for iodine transport. In addition, the magnitude of the initial iodine concentration in the RCS determines the amount of iodine entering the secondary. Assumptions regarding iodine $p l a t e o u t$ and dilution by feedwater flows influence the secondary iodine concentrations. Finally, assumptions regarding the values of the partition coefficient and the mixing fraction need to be made. The following sections describe the assumptions used in the iodine tracking model and the results of two sensitivity studies. The first sensitivity study investigates the iodine transport and release as a function of the assumed value of the partition coefficient. The second sensitivity study investigates the influence of reduced mixing, due to an assumed tube uncovery, on iodine transport and release.

\subsubsection{Assumptions of the Iodine-Tracking Model}

Initialization of the radioactivity tracking control system model requires identification of the radioactive component, specification of the initial concentrations in the primary and secondary systems, and specification of the transient concentrations in the primary, main feedwater, and auxiliary feedwater. For this calculation the radioactive component is I-13I. The concentration in the primary was assumed constant at $8.065 \times 10^{-9} \mathrm{~g} \mathrm{I} / \mathrm{kg}$ coolant. This corresponds to an iodine activity of 1 microcurie/g coolant. The initial iodine concentrations in the secondary liquid and vapor were assumed zero. The transient iodine concentrations in the main and auxiliary feedwater systems were also assumed zero. No plateout of iodine on any metal surfaces was assumed.

As a best estimate, the value for the mixing fraction was assumed to be $0.001 \%$. This value was based on data obtained from the MB-2 experimental facility. ${ }^{6}$ It is noteworthy that the MB-2 data showed that the primary 
break fluid became well mixed with the secondary fluid even in cases where the break location was exposed.

The partition coefficient is a measure of the relative amounts of iodine in the liquid and vapor phases. For FSAR calculations the partition coefficient is generally assumed to be 100 (meaning that on a mass basis the iodine is 100 times more concentrated in the liquid phase than in the vapor phase). The guidelines in the NRC Standard Review Plan ${ }^{7}$ allow the use of a partition coefficient of 100 as being conservative. The actual value of the partition coefficient is uncertain. For this reason a sensitivity study was conducted using partition coefficient values of 1,20 , and 100 .

\subsubsection{Partition Coefficient Sensitivity Study}

The effect of the partition coefficient value on iodine transport and release was investigated by varying the partiton coefficient: $P=1,20$, and 100. The iodine which entered the secondary through the tube rupture was distributed around the secondary based on the thermal hydraulic response of the secondary and the relative partitioning of iodine between the liquid and vapor phases. Immediately following the tube rupture there was buildup of iodine in each of the secondary regions as depicted in Figures 14 through 18 which show concentrations in the heater, the separator outlet, and the downcomer. As shown on each of these figures, the iodine concentration for the case of $p=1$ leveled off at a steady value until the reactor tripped at 483 seconds. This was different from the cases where $P=20$ and 100 , which showed steady increases in iodine concentrations throughout the system until the time of reactor trip. For the case of $P=1$, after the initial buildup a situation was reached in which all the iodine entering the secondary from the primary was carried out of the secondary through the steam line. This was a result of the large iodine-carrying capacity of the steam when $P=1$. For the other two cases the iodine was preferentially retained in the liquid phase which was not exiting the system. Therefore the concentrations continued to increase until the time of reactor trip. The concentration responses after reactor trip can be explained by the mass redistribution which occurred between the downcomer and the boiler, and the dilution effect due to auxiliary feedwater which was initiated at $543 \mathrm{~s}$. 


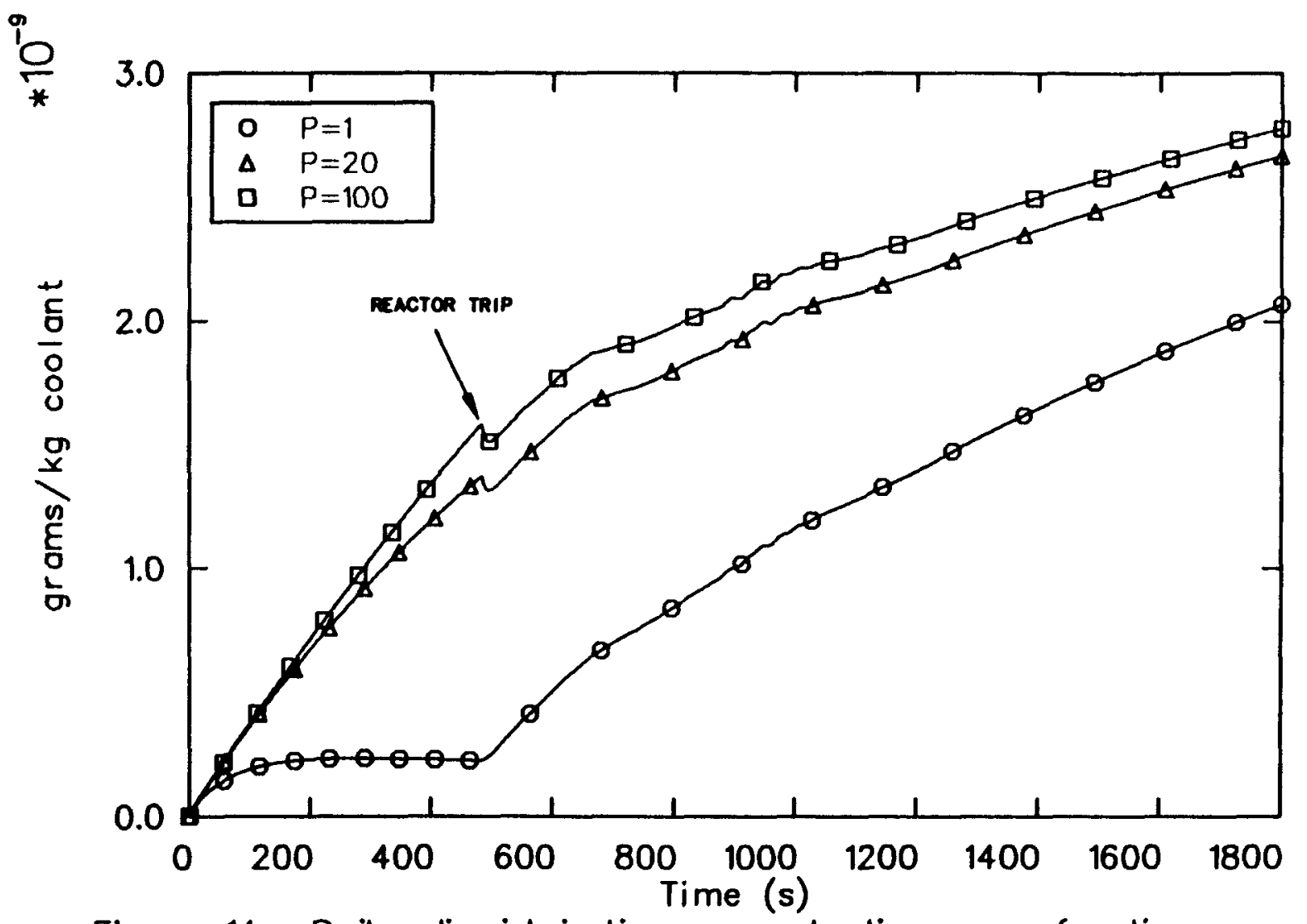

Figure 14. Boiler liquid iodine concentrotion os a function of portition coefficient. 


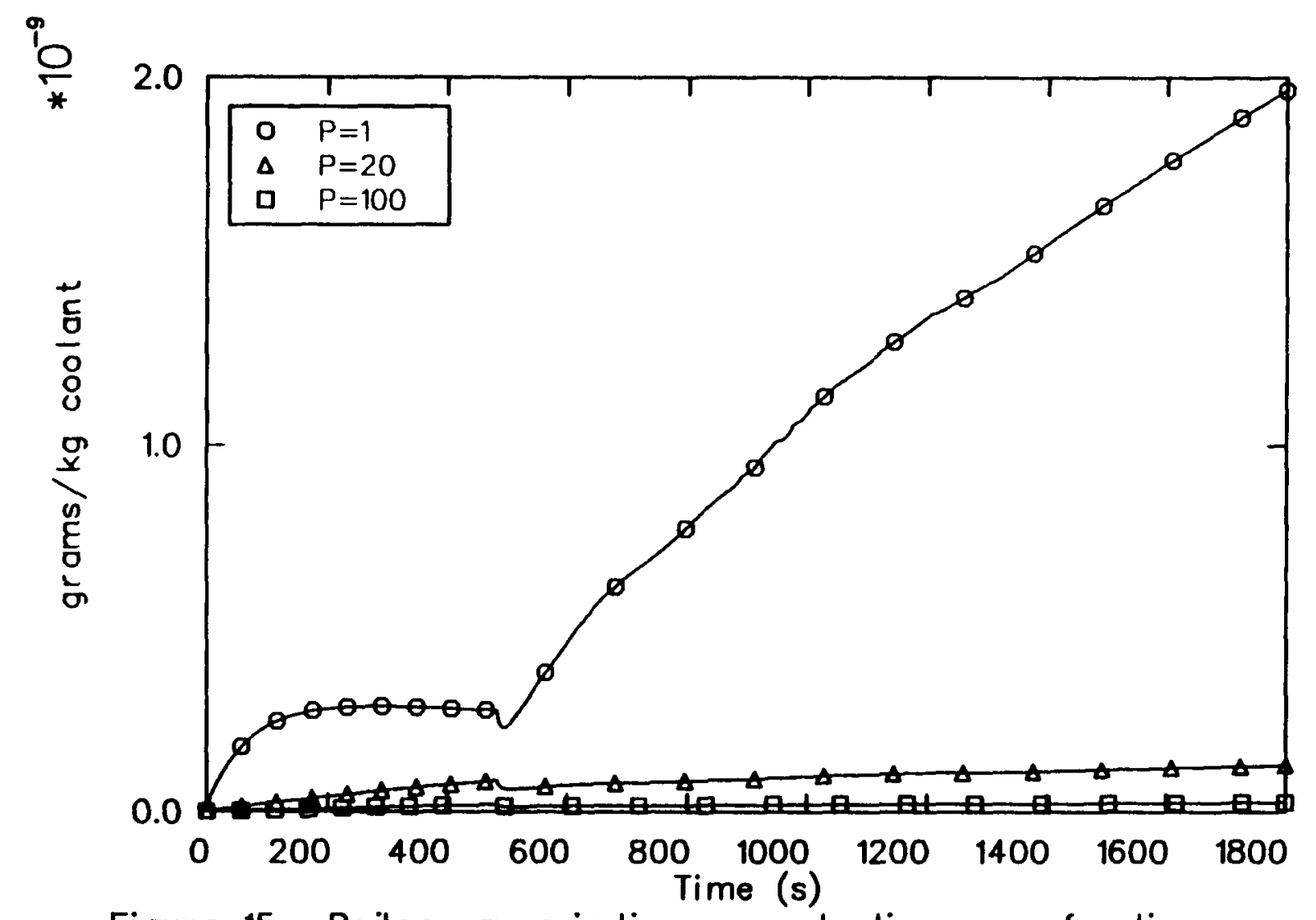

Figure 15. Boiler vapor iodine concentrotion os a function of portition coefficient. 


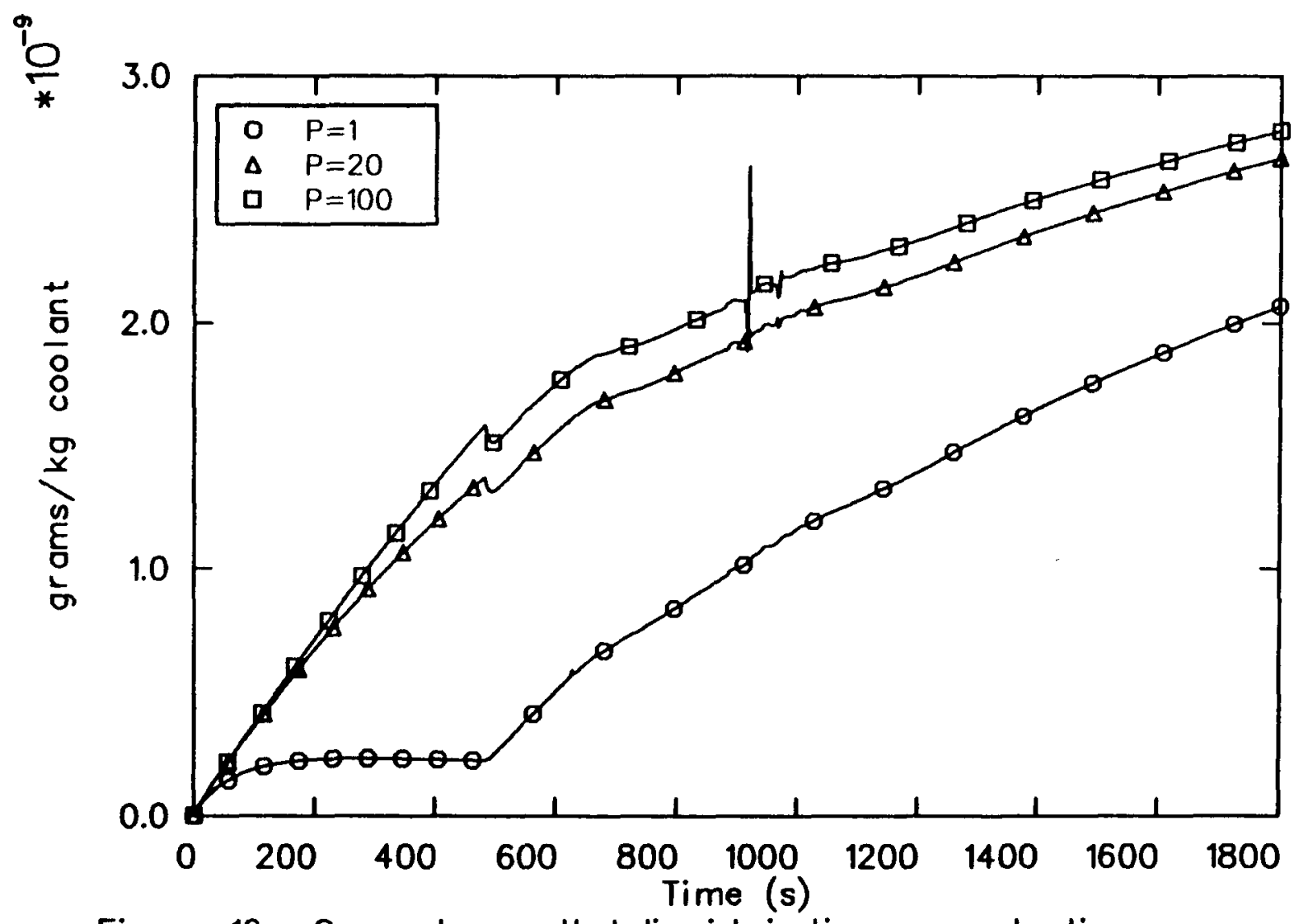

Figure 16. Separator outlet liquid iodine concentration as a fraction of parrtition coefficient. 


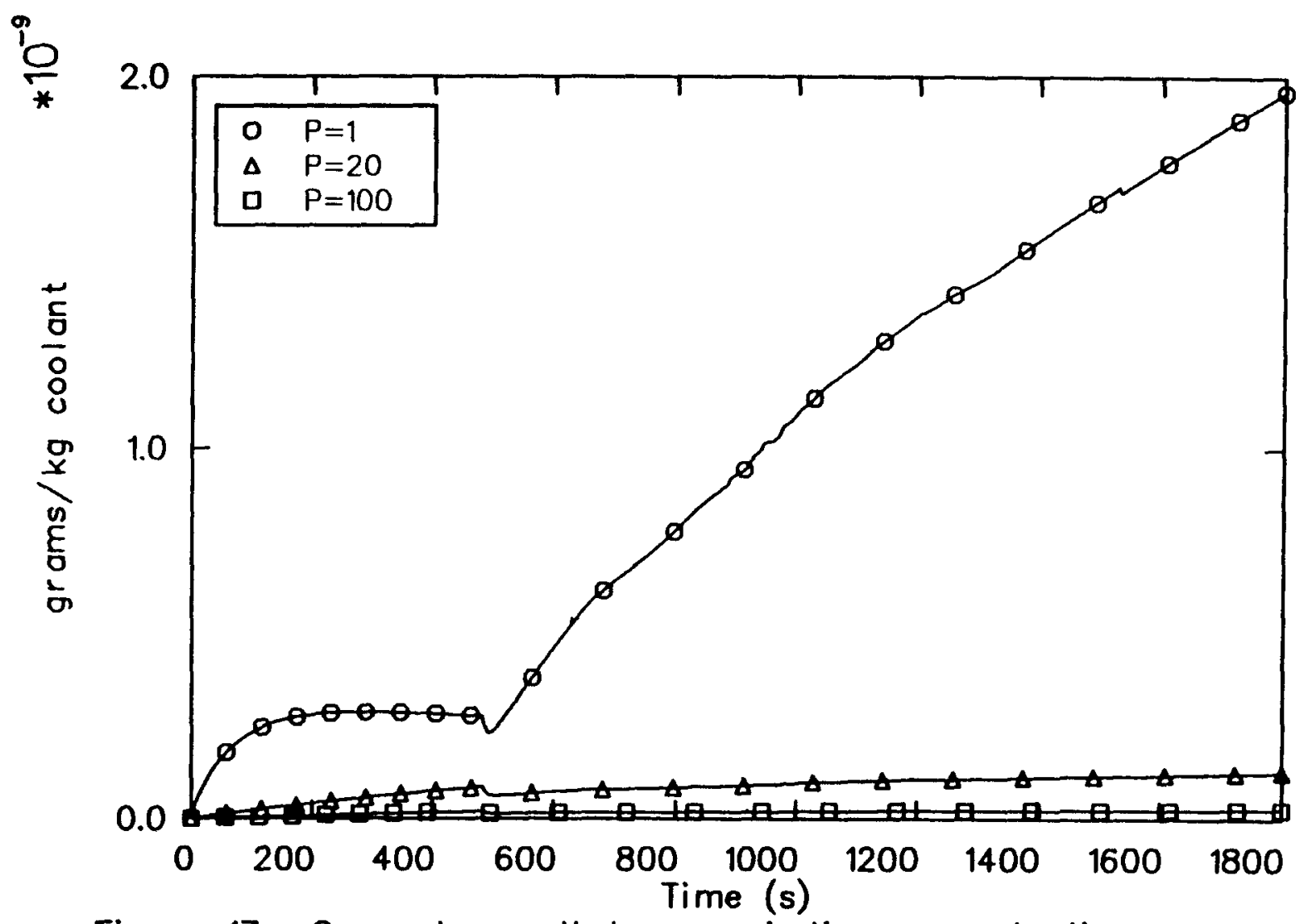

Figure 17. Seporator outlet vapor iodine concentration as a function of portition coefficient. 


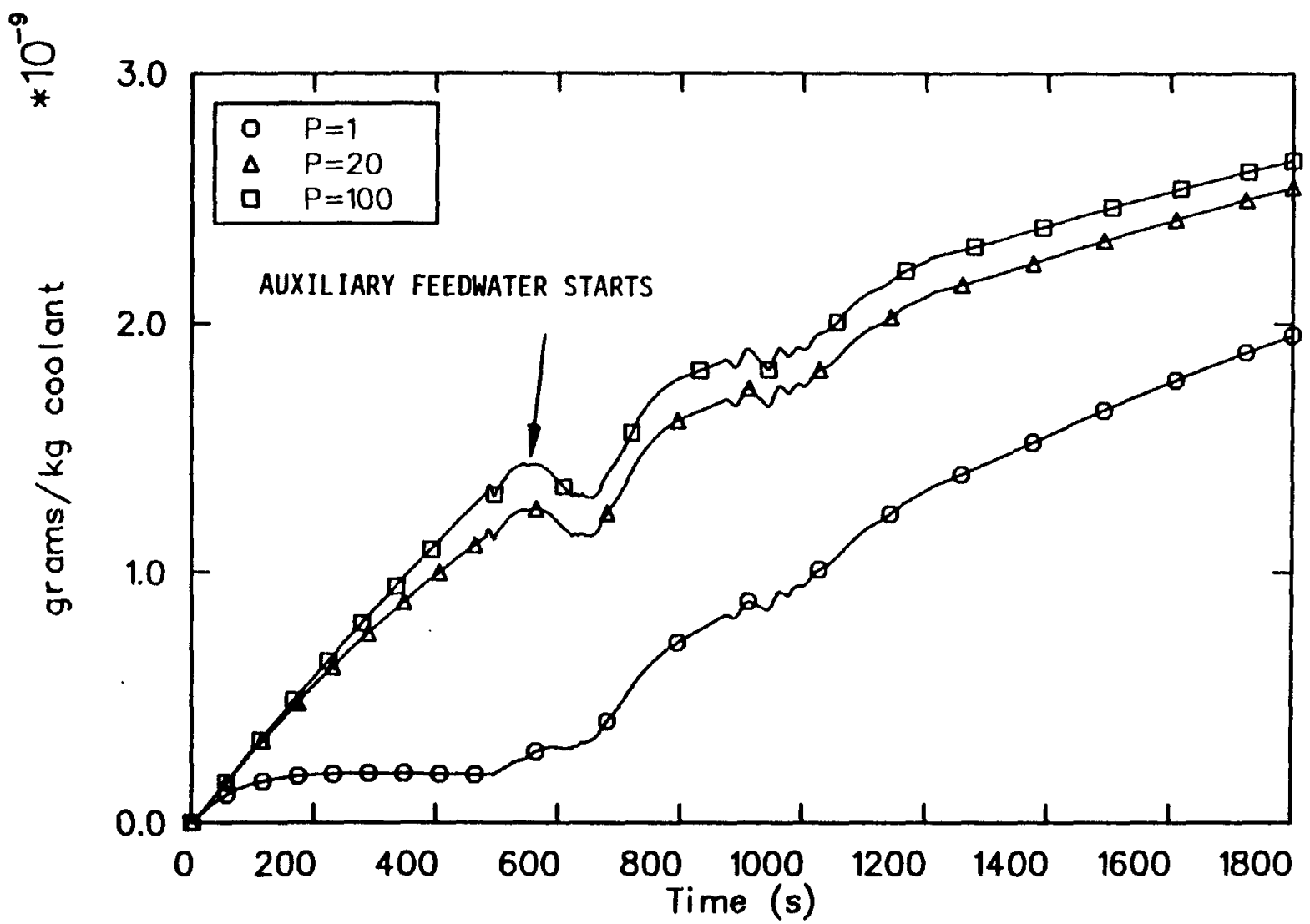

Figure 18. Downcomer iodine concentration as a function of partition coefficient. 
After reactor trip liquid mass was transferred rapidly from the downcomer to the boiler. The downcomer concentration was less than that of the boiler because the rupture flow entered into the boiler region. The dilution of the boiler liquid by the less concentrated downcomer liquid caused the slight concentration decreases seen in the boiler and separator outlet (Figures 14 through 17).

In the downcomer (Figure 18) the concentration continued to increase until auxiliary feedwater began at $543 \mathrm{~s}$, diluting the downcomer. This dilution continued until the reestablishment of recirculation flow circulated the more concentrated boiler fluid into the downcomer via the separator.

The integrated iodine released to the atmosphere is depicted in Figure 19. The qualitative response is as expected. More iodine was released when the iodine was preferentially partitioned into the vapor phase because vapor was released through the steam generator PORVs.

As noted in the presentation of the thermal hydraulic results, the vapor (and therefore, iodine) release after $1300 \mathrm{~s}$ was a consequence of the continued auxiliary feedwater injection. Further discussion of this release is provided later.

Table 3 shows the magnitude of iodine releases at $1800 \mathrm{~s}$. The results indicate that decreasing the partition coefficient from 100 to 1 did not result in an increase in the amount of released iodine by a factor of 100 . Iodine release is not linearly scaled to the value of the partition coefficient. Figures 20 and 21 indicate why this is so. Prior to reactor trip at $483 \mathrm{~s}$, for the case of equal iodine partitioning between the vapor and the liquid, Figure 20 shows that the vapor iodine concentration leveled off. A steady condition was reached in which all of the iodine from the primary break entering the secondary system was being transported in the vapor phase out through the steam line. This was a result of the large iodine-carrying capacity of the vapor phase. For the case of $P=100$ (Figure 21), most of the iodine from the primary break was retained in the secondary liquid phase. Both the liquid and the vapor concentrations 


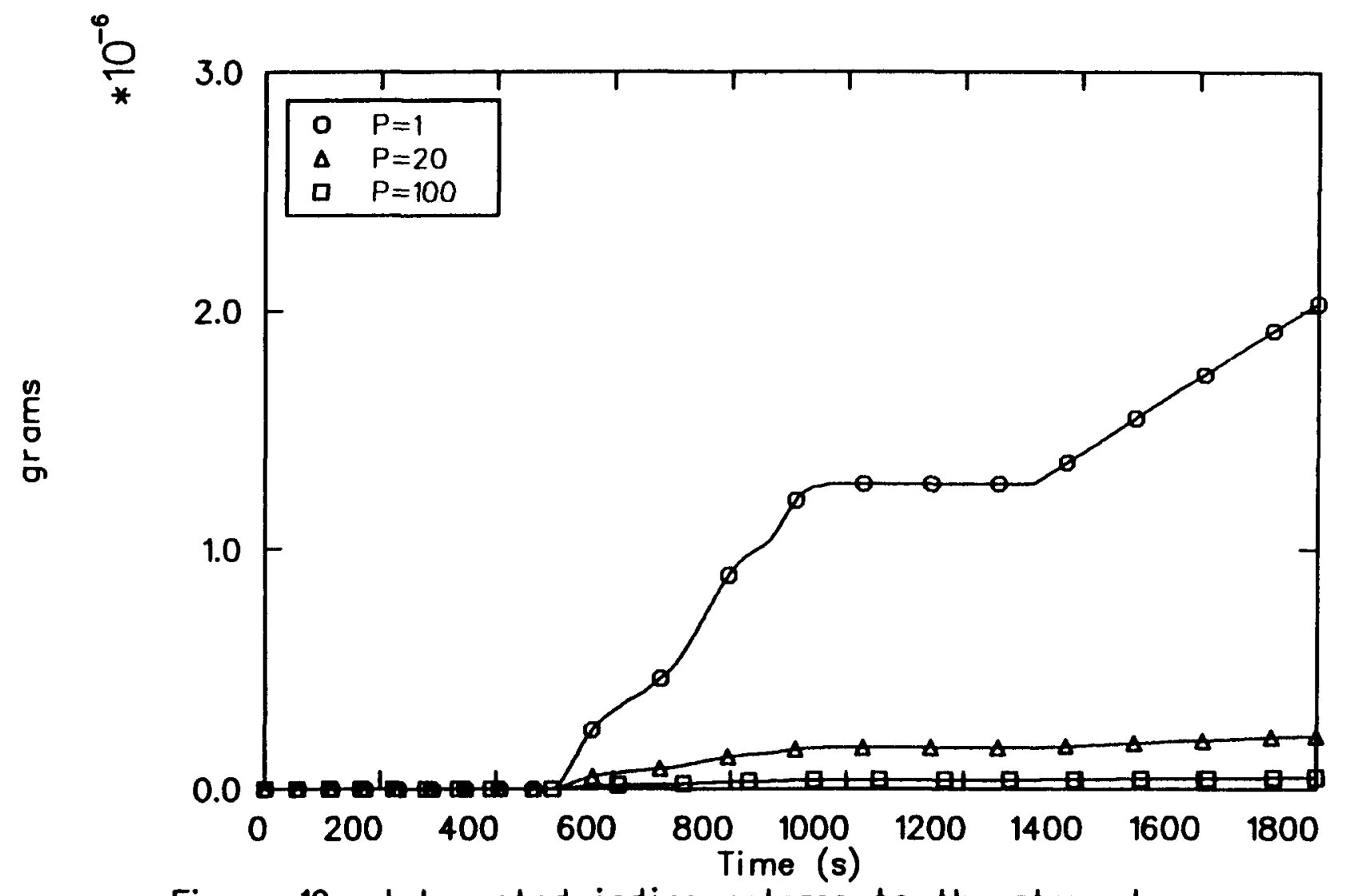

Figure 19. Integrated iodine release to the atmosphere as a function of partition coefficient. 
$w$

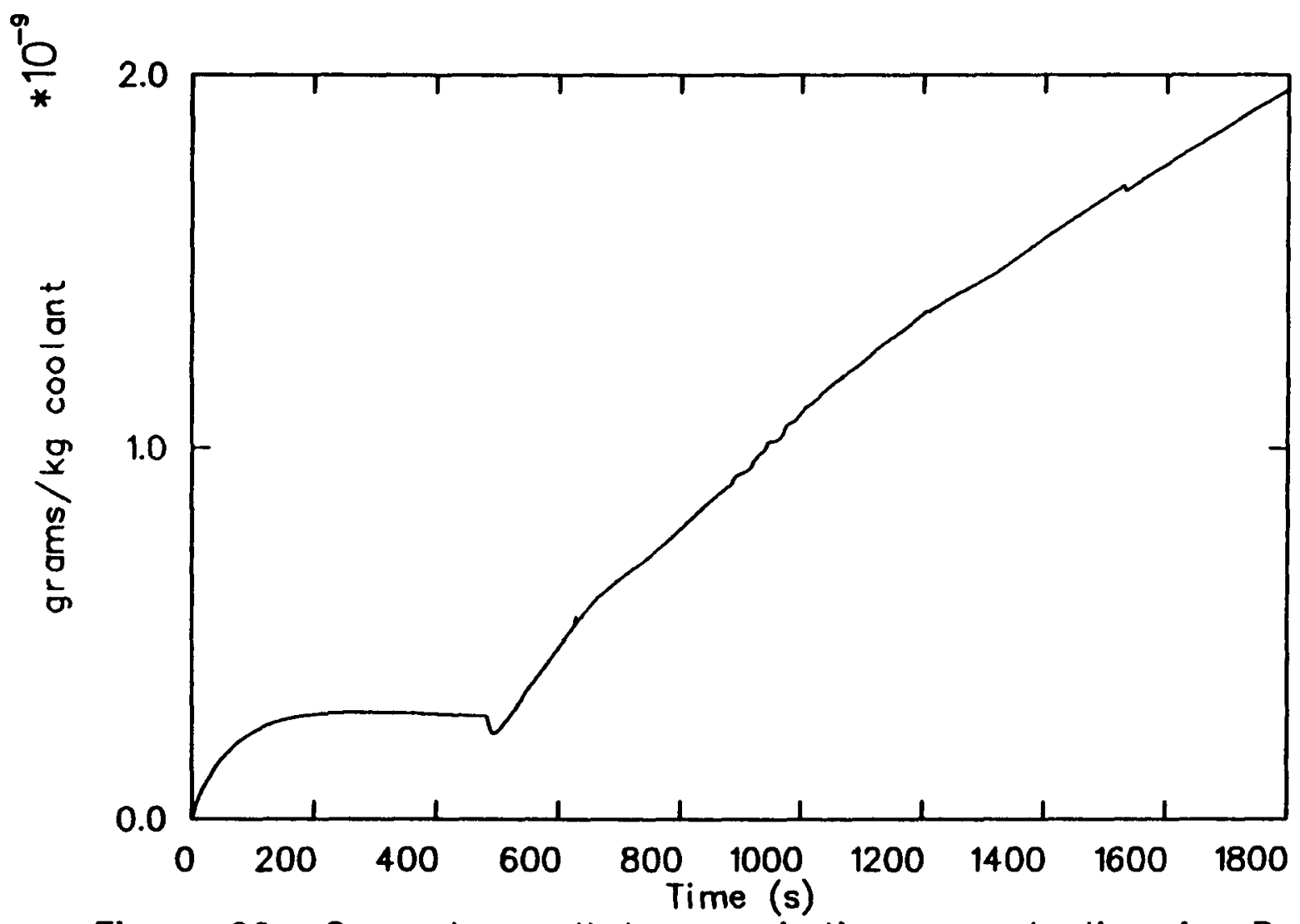

Figure 20. Separator outlet vapor iodine concentration for $P=1$. 


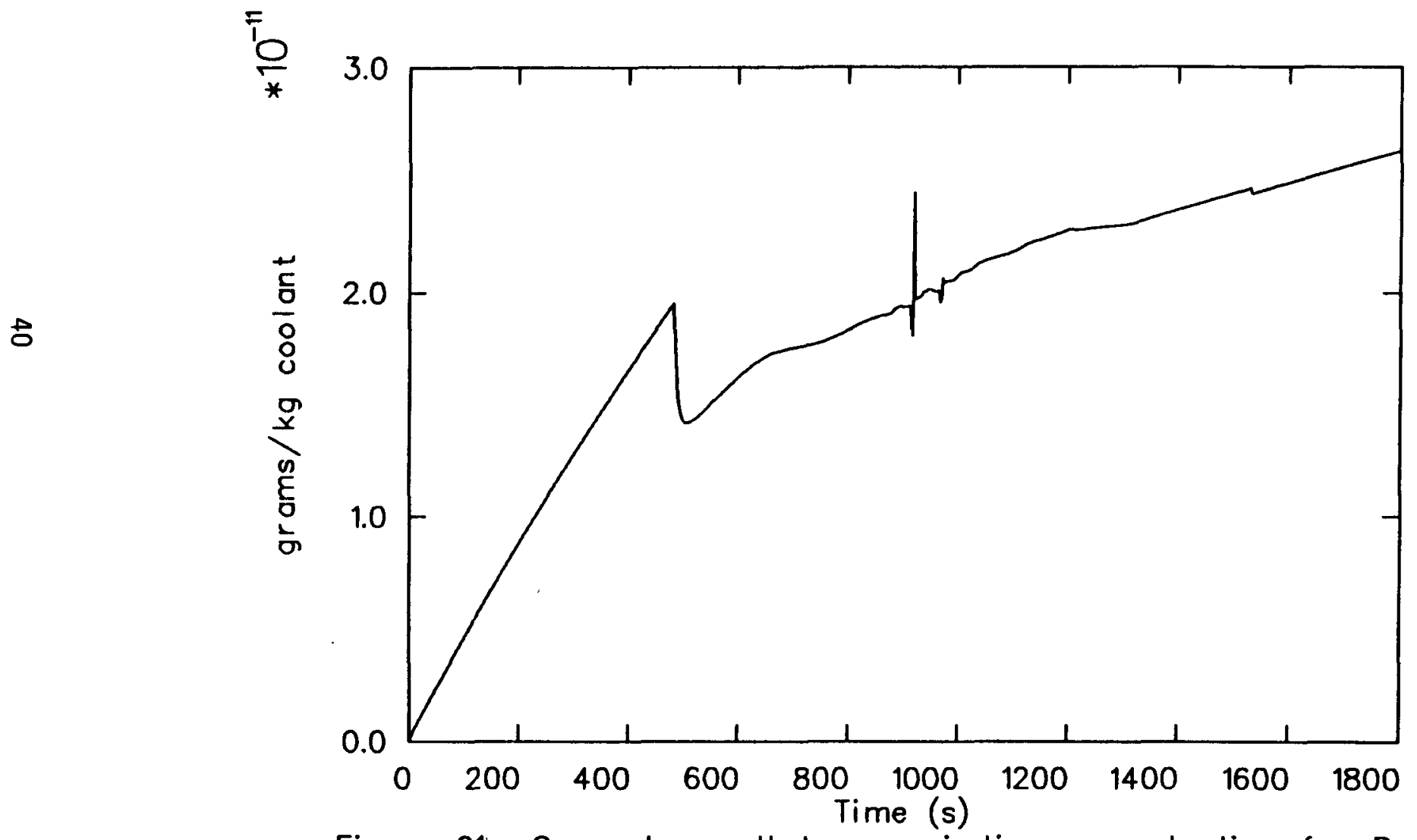

Figure 21. Separator outlet vapor iodine concentration for $P=100$. 
increased linearly prior to reactor trip.

At the time of reactor trip, the vapor iodine concentration for the case of $P=1$ was about 15 times the vapor iodine concentration for the case of $P=100$. The post-trip vapor release to the environment was more highly concentrated with iodine for $P=1$ as compared to $P=100$, but it was not 100 times more concentrated. At the end of the calculation (1800 s) the integrated iodine release for the case of $P=1$ was 42 times the amount when $P=100$.

\subsubsection{Mixing Fraction Sensitivity Study}

A sensitivity study was performed to evaluate the effect of the mixing fraction on the iodine transport and release. The mixing fraction was adjusted based on the amount of time that the collapsed liquid level was calculated to be below the top of the tubes. For the study the partition coefficient was assumed to be 100 . Prior to reactor trip the mixing fraction was assumed to be $0.001 \%$. Between 483 and $675 \mathrm{~s}$ the mixing fraction was set to 1.0. During this time the liquid flow from the tube rupture was assumed to enter directly into the separator without mixing with the secondary fluid. Based on the liquid mass calculated in the steam generator secondary it was estimated that at $675 \mathrm{~s}$ there would be enough collapsed liquid mass to cover the top of the U-tubes without any credit taken for voids beneath the surface. The liquid mass required for this purpose was calculated to be $102,700 \mathrm{lbm}$. Therefore after $675 \mathrm{~s}$ the mixing fraction was reset to be $0.001 \%$.

Figures 22 through 26 show the boiler, separator outlet, and downcomer concentrations. Jetting of primary liquid directly into the separator caused a relative increase in downcomer concentration at the expense of the boiler concentration. The separator outlet concentrations also increased during the time of assumed tube uncovery as a result of the primary liquid entering directly into the separator.

Figure 27 shows the integrated iodine released through the steam generator PORV for the two cases. As expected the jetting of primary fluid 


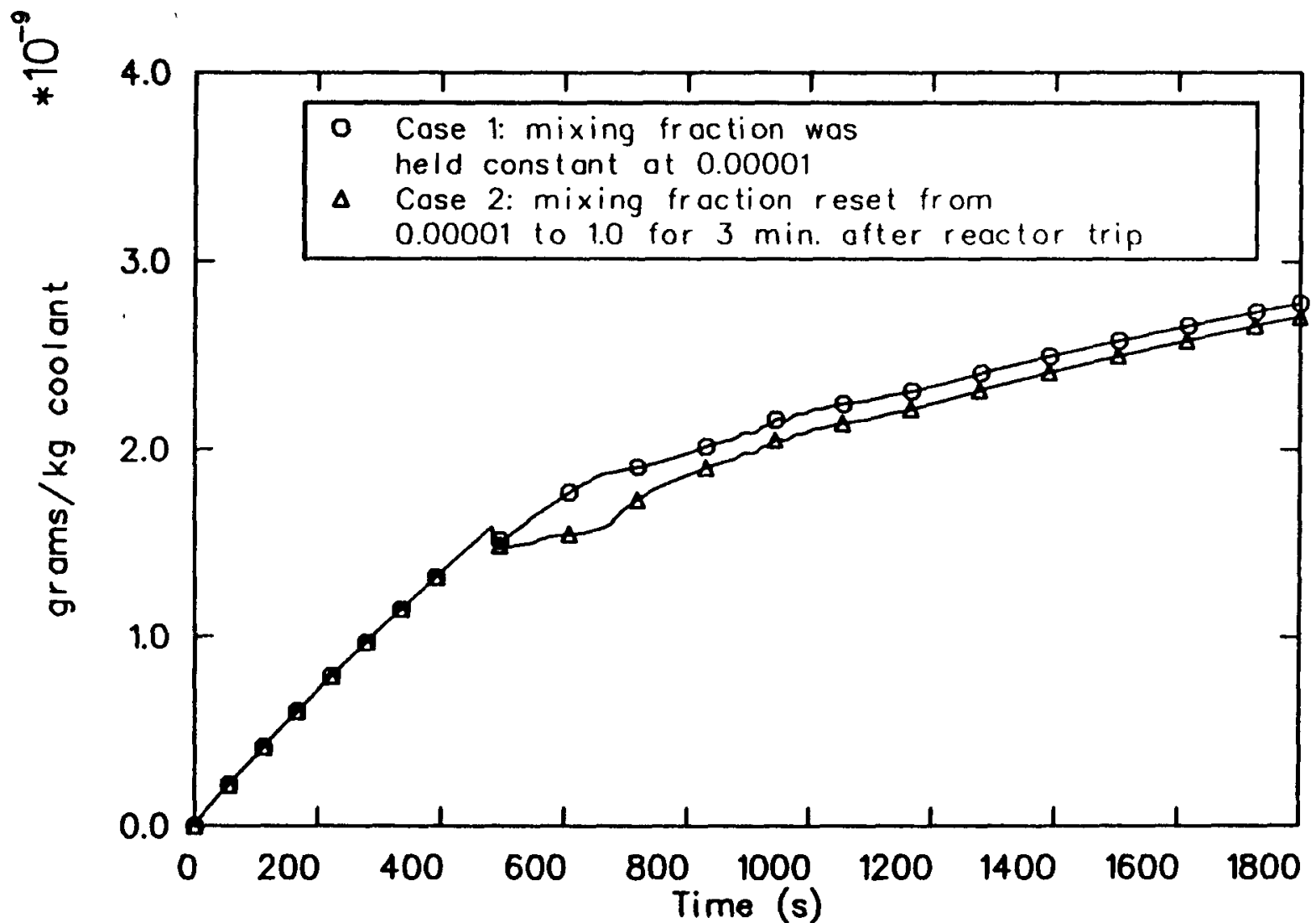

Figure 22. Boiler liquid iodine concentration: mixing fraction sensitivity study. 


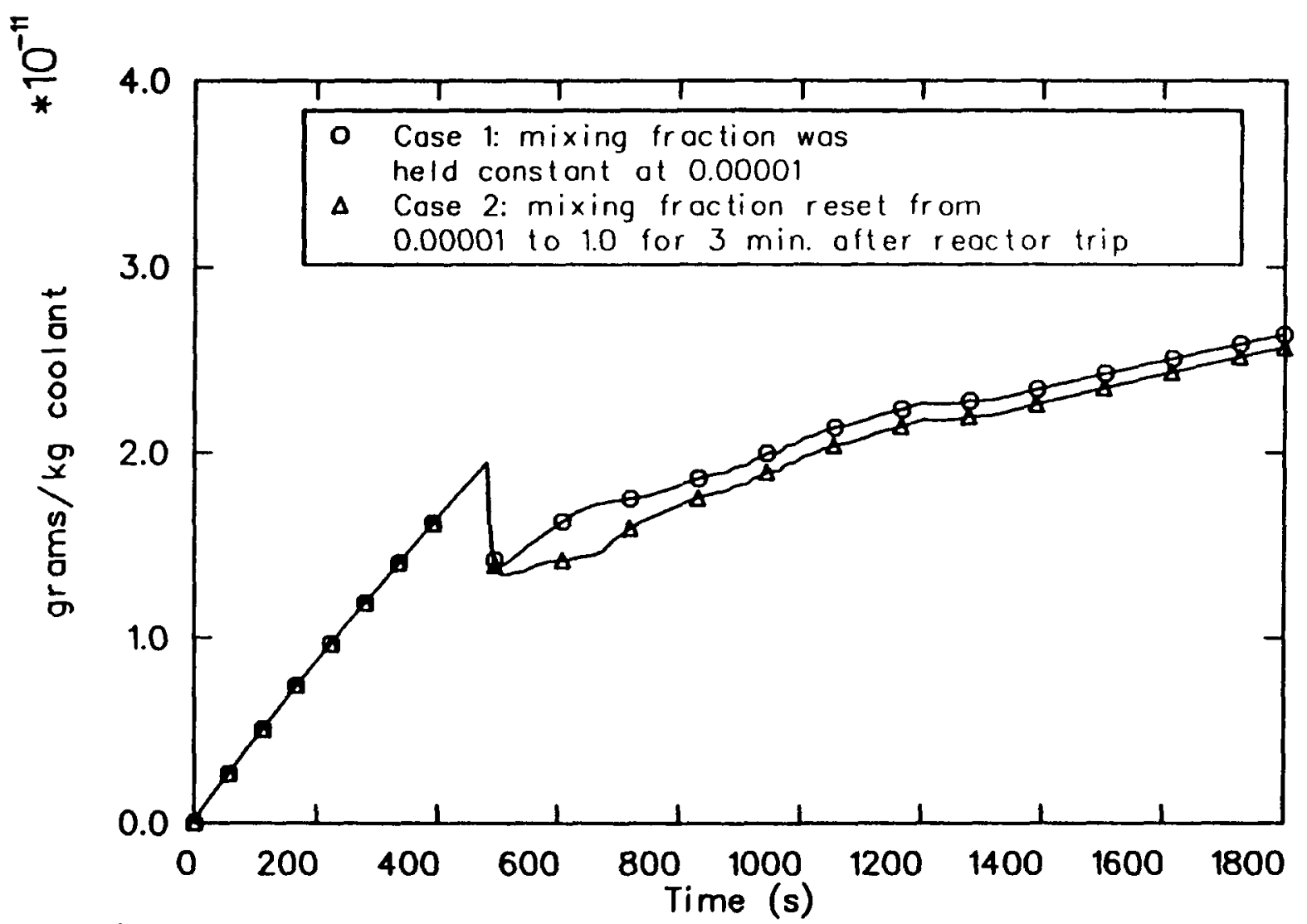

Figure 23. Boiler vapor iodine concentration: mixing fraction sensitivity study. 


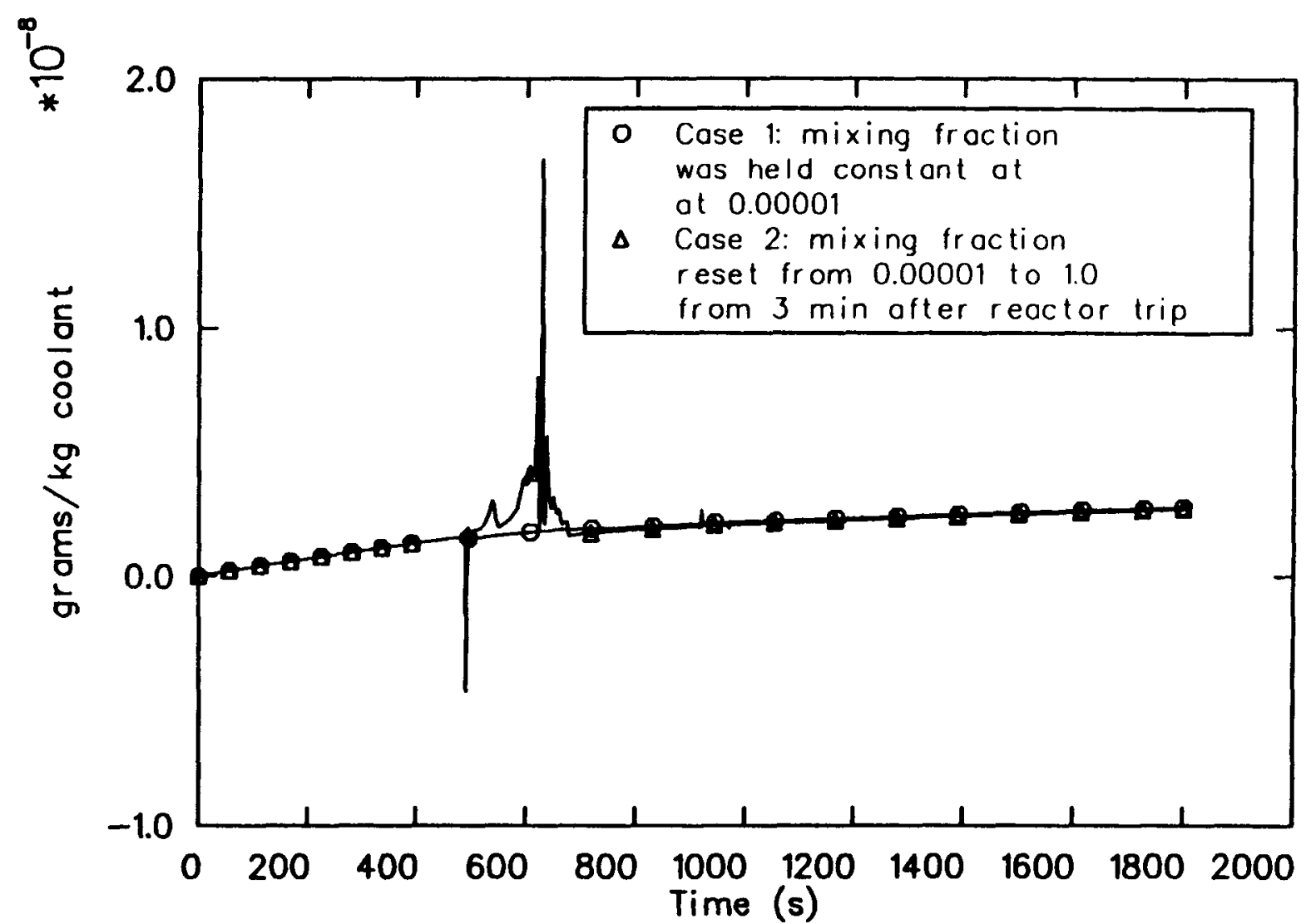

Figure 24. Separator outlet liquid iodine concentration: mixing froction sensitivity study. 


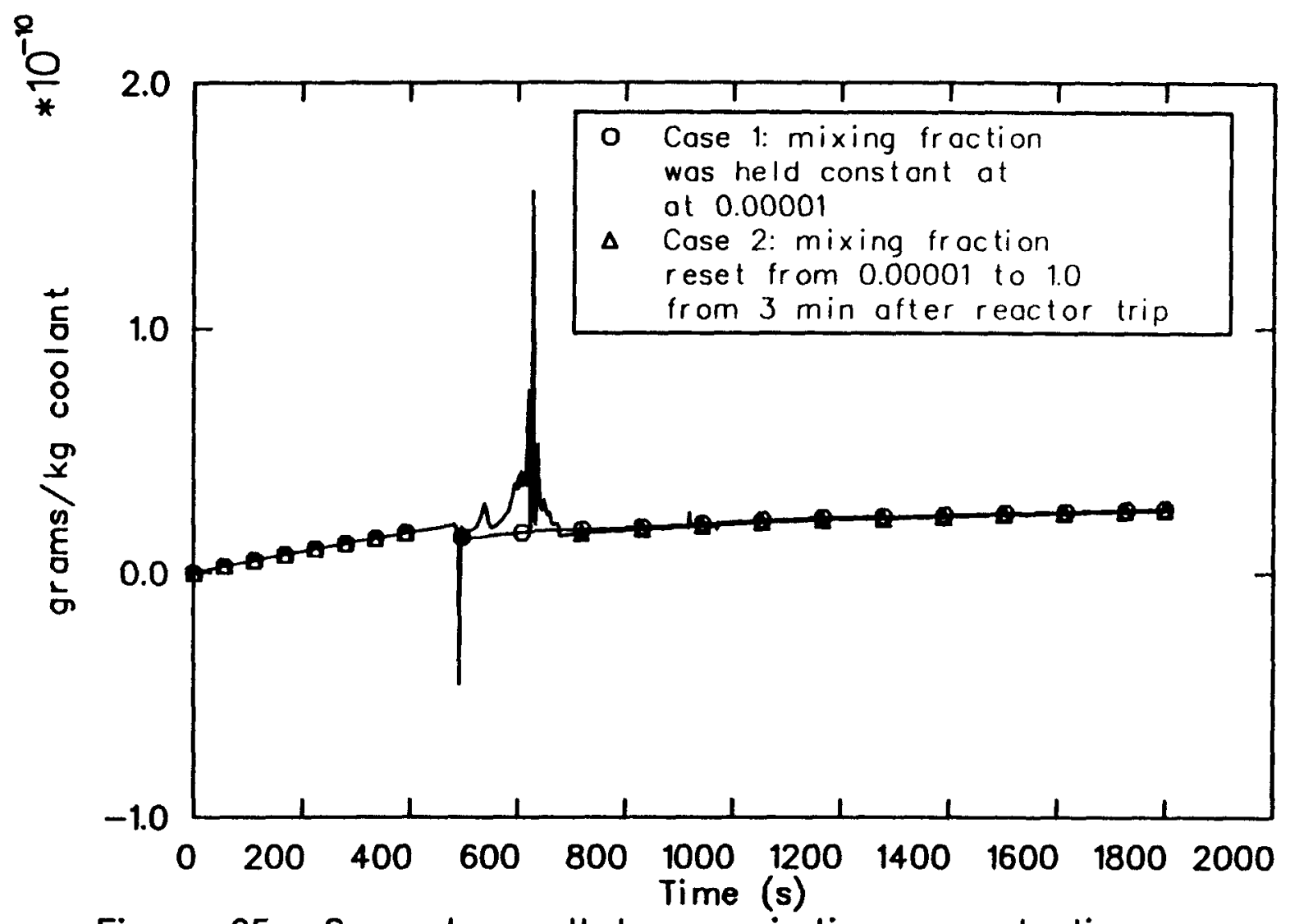

Figure 25. Separator outlet vapor iodine concentration: mixing fraction sensitivity study. 


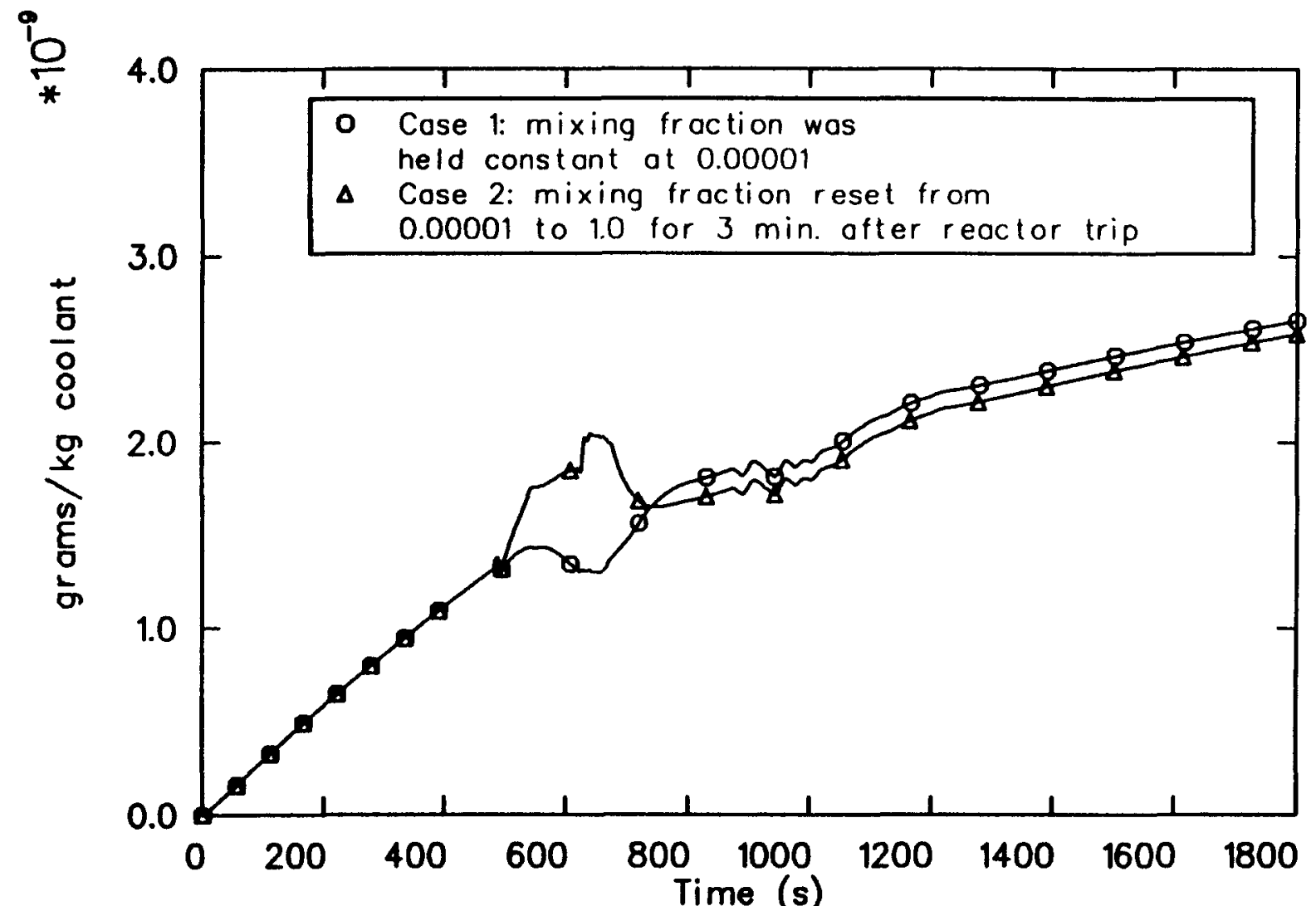

Figure 26. Downcomer iodine concentration: mixing fraction sensitivity study. 


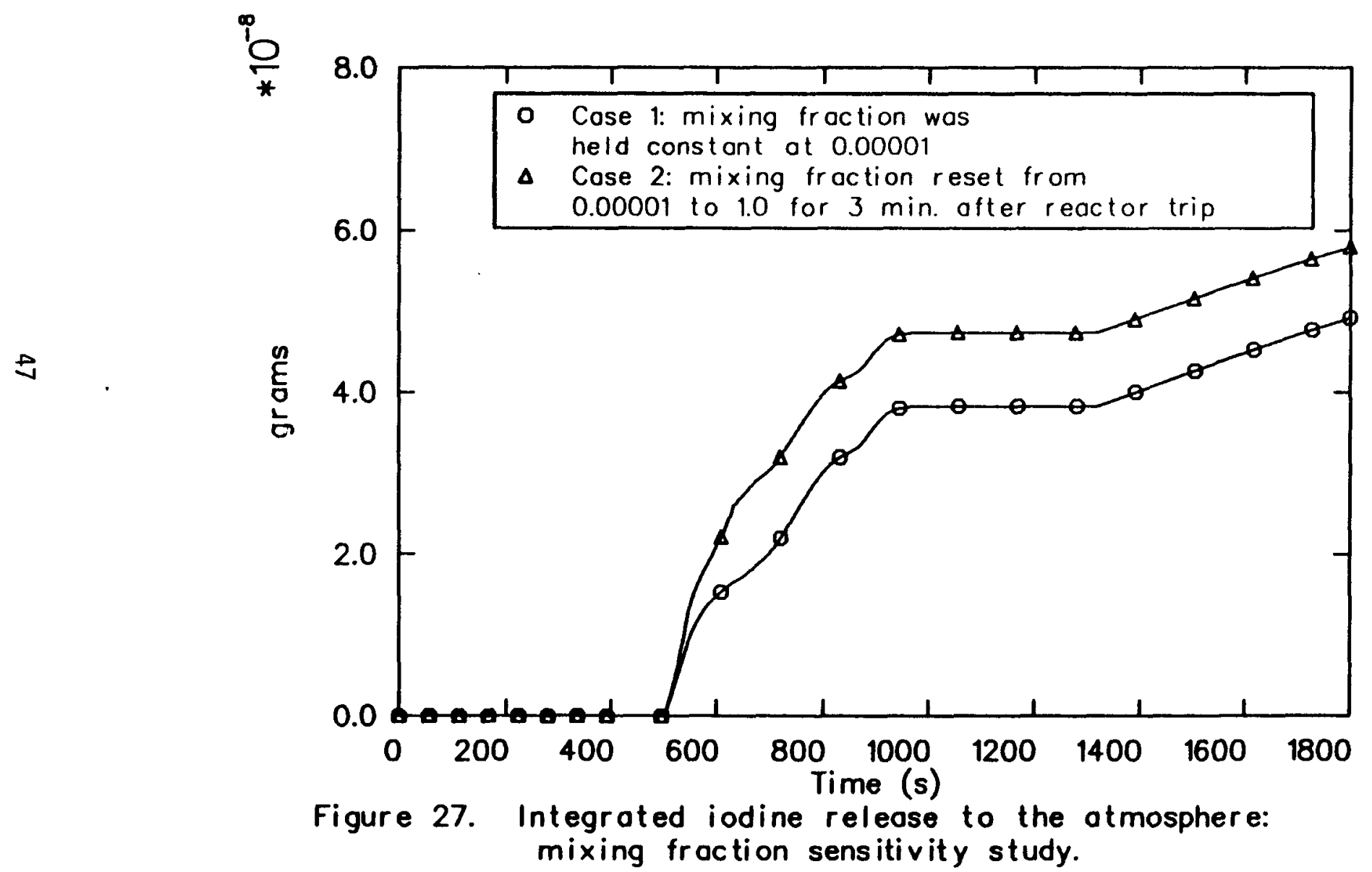


P

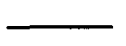

1

20

100 grams to atmosphere

$2.03 \times 10^{-6}$

$2.23 \times 10^{-7}$

$4.91 \times 10^{-8}$
Curies to atmosphere

0.25

0.028

0.006

Note: Mixing fraction $=0.001 \%$

TABLE 4. IODINE RELEASE FOR DIFFERENT ASSUMPTIONS REGARDING TUBE UNCOVERY

Assumption

grams to atmosphere

Curies to atmosphere

Case 1

$4.91 \times 10^{-8}$

0.006

Case 2

$5.79 \times 10^{-8}$

0.007

Note: $P=100$.

Case 1: Mixing fraction was held constant at $0.001 \%$ based on no tube uncovery on a mixture level basis.

Case 2: Mixing fraction reset from $0.001 \%$ to 1.0 for 3 minutes after reactor trip based on tube uncovery on a collapsed level basis. 
directly into the separator resulted in more iodine release to the environment. However the difference was not large. Table 4 shows the magnitude of iodine releases and the activity associated with each release.

The results presented in Table 4 indicate that the effect of assuming tube uncovery for a portion of the transient was not major. The assumption of an approximately three minute period of tube uncovery, based on collapsed liquid level, resulted in an increase in the amount of released iodine of about $20 \%$.

\subsection{Iodine Dose Estimates}

The dose to the public was estimated using the iodine release results of Table 4 . A hand calculation was used as described in Reference 11 . The following equation was used:

Dose $=\left(B . R_{.}\right) *(L . F) *.(X / Q) *(D . C . F)$

where

$$
\begin{aligned}
& \text { B.R. } \quad=\text { breathing rate }=3.47 \times 10^{-4} \mathrm{~m}^{3} / \mathrm{s} \\
& \text { L.F. } \quad=\text { leakage factor }(C i) \\
& X / Q \quad=\text { dispersion factor }=8.14 \times 10^{-4} \mathrm{~s} / \mathrm{m}^{3} \\
& \text { D.C.F. }=\text { dose conversion factor }=1.07 \times 10^{-3} \mathrm{mrem} / \mathrm{pCi}
\end{aligned}
$$

The dose conversion factor used was that for a thyroid dose as recommended by ICRP $-30^{12}$. The dispersion factor was obtained from the Surry UFSAR ${ }^{3}$.

The dose calculation was performed for the iodine release results described above which assumed an initial RCS iodine activity of 1 microcurie/g coolant. In addition, a dose calculation was performed for the case of an assumed pre-accident iodine spike. The pre-accident iodine spike was assumed to raise the RCS iodine activity to 20 microcurie/g, a value slightly higher than the maximum historical iodine spike reported in Reference 11. 
Results of the iodine dose analyses are presented in Table 5 . With a pre-accident iodine spike, the maximum thyroid dose was $1.5 \cdot$ rem, for an assumed partition coefficient of 1 . For a partition coefficient of 100 , with a pre-accident iodine spike, the thyroid dose was $0.036 \mathrm{rem}$. 
TABLE 5. CALCULATED IODINE DOSE AS A FUNCTION OF PARTITION COEFFICIENT

\begin{tabular}{lll}
\hline $\mathrm{P}$ & $\begin{array}{c}\text { Thyroid - no spiking } \\
(\text { rem })\end{array}$ & $\begin{array}{c}\text { Thyroid - pre-accident spike } \\
\text { (rem) }\end{array}$ \\
\cline { 2 - 3 } 1 & 0.076 & 0.17 \\
10 & 0.008 & 0.036 \\
100 & 0.002 & \\
\hline
\end{tabular}

a. Initial iodine activity $=20$ microcurie $/ g$ cootant 


\section{DISCUSSION}

The motivation for the analyses presented in this report was twofold: (1) Assess the likelihood of tube bundle uncovery following reactor trip during a steam generator tube rupture, and (2) Calculate the magnitude of iodine release to the environment for a steam generator tube rupture transient and determine the sensitivity of release to iodine partitioning, and the mixing of primary break fluid with the secondary fluid.

The calculation of the magnitude of iodine release is dependent on the scenario assumed for the progression of the transient. The philosophy adopted for this work was to use assumptions similar to those used for the design basis accident in the Surry UFSAR. The present analysis also assumed that the operators did not act to control level in the affected steam generator. Operator action to prevent atmospheric steam release from the affected steam generator was assumed to take place within 30 minutes of transient initiation.

The remainder of this section presents discussions of the results of the analyses, and attempts to delineate how the scenario assumptions chosen may affect iodine release.

\subsection{Tube Bundle Uncovery}

The RELAP5 calculation indicated that the post-trip mixture level was sufficient to maintain continuous coverage of the tubes. However previous comparisons of RELAP5-calculated and experimental data in core boiloff situations have indicated code weaknesses in matching experimental mixture level behavior. For this reason a hand calculation was performed to independently check the RELAP5 mixture level. The calculation utilized the method of Sun $^{8}$ and a voidage correlation of Cunningham and Yeh. ${ }^{9}$ The calculation was made for conditions at $530 \mathrm{~s}$. This corresponded to a time when it appeared possible that the tubes could be uncovered. For this calculation it was assumed that there was a linear heat transfer rate across the $U$-tubes, and a low boiler flow. The results of the hand calculation indicated a mixture level which was about two feet above the top of the tube 
bundle. This is consistent with the RELAP5 results which showed the post-trip void fraction in the volume above the $U$-tubes to be less than 0.3 (Figure 8).

Both the RELAP5 calculation and the estimate from a hand calculation indicate a steam generator mixture level sufficient to prevent tube bundle uncovery following reactor trip at Surry.

\subsection{Modelling Deficiencies}

Two modelling deficiencies identified earlier were: no modelling of charging flow, and no modelling of pressurizer heaters. Both of these systems would act to retard the rate of primary system depressurization following the initiation of the tube rupture and cause the reactor trip to occur later in time. This delay would allow more iodine to be transferred from the primary to the secondary prior to reactor trip. In assessing the effect on overall atmospheric iodine release, two effects need to be considered. For the case of equal partitioning of the iodine between the liquid and the vapor, the iodine concentrations in the secondary reached an early steady-state value because of the large iodine-carrying capacity of the vapor. Therefore the delay in the time of reactor trip would probably not have a significant direct effect on the atmospheric release via the affected steam generator. The delay would however allow more iodine to be passed into the steam line and feedwater system.

In the case where iodine is preferentially partitioned into the liquid phase, the delay in reactor trip will provide time for the iodine concentrations in the secondary liquid and vapor to increase. Most of the entering iodine will be retained in the liquid, nevertheless the eventual atmospheric release in the vapor will be higher.

An estimate of the effect of charging flow and pressurizer heating on the amount of trip delay was made by performing an analogous single tube SGTR RELAP5 calculation for the H. B. Robinson plant. The H. B. Robinson RELAP5 input deck ${ }^{5}$ contains models of the charging flow and pressurizer heaters. For the H. B. Robinson transient, reactor trip occurred at $535 \mathrm{~s}$, 
a delay of $51 \mathrm{~s}$ from the time for Surry. Caution must be taken in making a direct comparison because the potential exists for significant difference in the charging flow between the two plants.

An additional effect not considered in the analyses is the potential buildup of iodine concentration in the main feedwater system prior to reactor trip. The present analyses assumed that the concentration of iodine in the main feedwater remained constant at zero. If a buildup of iodine concentration in the main feedwater occurred, there would be additional iodine present in the steam generator at the time of reactor trip. This would result in a larger amount of iodine released to the environment.

\subsection{Operator Actions}

As indicated in Reference 4, a steam generator tube rupture, unlike other loss of coolant accidents, demands substantial operator involvement early in the event. Operator actions are necessary to limit radiological release and prevent steam generator overfill.

The general sequence of operator actions for a Westinghouse PWR can be determined from the emergency response guidelines of Reference 4 . The major categories of actions are: (1) Identify and isolate the ruptured steam generator, (2) Cool down to establish RCS subcooling margin, (3) Depressurize RCS to restore inventory, (4) Terminate SI to stop primary-to-secondary leakage, and (5) Prepare for cooldown to cold shutdown.

The RELAP5 calculation performed for the present analys is was terminated at 30 minutes based on the assumption that operator actions would be taken to isolate the affected steam generator and prevent further steam release form it after 30 minutes. This assumption is consistent with the assumption made in the FSAR for a steam generator tube rupture. A previous calculation for an SGTR at a Combustion Engineering PWR indicated that, once the operators began to take action, about 10 minutes were required to isolate the affected steam generator and prevent further steam release from it. 10 Despite differences between Combustion Engineering and Westinghouse PWRs, it is likely that a similar length of time would be required for a 
Westinghouse PWR.

Although the present RELAP5 calculation was terminated at 30 minutes based on the assumption of operator actions, operator actions during the 30 minutes were not modelled. As a result, the separator of the affected steam generator became liquid-full. The steam (and iodine) release seen in the calculation after $1300 \mathrm{~s}$ resulted from the volumetric displacement of the steam bubble at the top of the steam generator by the incoming auxiliary feedwater. If the operators were assumed to throttle auxiliary feedwater, this release would not occur. However, earlier throttling of auxiliary feedwater could result in additional steam release at earlier times due to boiling in the steam generator secondary system. The feedwater provides a source of subcooling which reduces boiling.

The present calculation may not provide the most conservative estimate of steam release for a SGTR. As discussed in further detail below, the timing of operator actions may influence the amount of release.

Nevertheless the present calculation provides an estimate of the magnitude of steam release for an SGTR scenario similar to that described in the FSAR. In addition, the sensitivity studies indicate the relative importance of partitioning and primary/secondary mixing on the amount of iodine released to the environment.

\subsection{Secondary Steam Release Comparisons}

The iodine released to the atmosphere is transported in the steam released through the secondary relief valves. The amount of steam release is dependent on the exact progression of the tube rupture scenario. In the case of calculated values, the assumptions determine the amount of release. Inspection of FSAR values for. steam release from the broken steam generator indicates significant variation: $57000 \mathrm{lbm}$ for $\mathrm{H}$. B. Robinson ${ }^{13}, 36000 \mathrm{lbm}$ for Sequoyah ${ }^{14}, 47000 \mathrm{lbm}$ for Resar ${ }^{15}$, and 20300 for Surry ${ }^{3}$. In the present calculation, the amount of steam release from the broken steam generator $(6000 \mathrm{lbm})$ is significantly lower than the FSAR values shown above. Because the FSAR calculation assumptions are not explicitly stated, it is not possible to conclusively determine the source of the difference. 
An energy balance on the broken steam generator indicated that the $6000 \mathrm{lbm}$ steam release was consistent with the energy flows in the steam generator. One important effect is the amount of energy absorbed by the subcooled auxiliary feedwater when being heated to the secondary saturation temperature. The importance of this effect can be deduced by comparison of the steam generator tube rupture calculations reported in References 16 and 17. These analyses were for the Zion-1 plant, a Westinghouse 4-10op PWR. The calculation reported in Reference 16 assumed a single tube rupture with operator action to throttle the auxiliary feedwater when the broken steam generator level had recovered. The flow out the broken steam generator relief valve was $260001 \mathrm{bm}$. The analysis presented in Reference 17 assumed a failure of the auxiliary feedwater control system such that $2 / 3$ of the flow was to the broken steam generator. In this case the steam release was approximately $5001 \mathrm{bm}$. The significant difference in steam release is attributable to the difference in the auxiliary feedwater flow. As more energy is absorbed in heating the auxiliary feedwater, less is available for steam production.

The calculation for the Surry PWR presented in this report assumed $50 \%$ auxiliary feedwater flow with no throttling. Auxiliary feedwater throttling would likely result in additional steam release with a corresponding increase in the amount of atmospheric iodine release.

\subsection{Plant-to-Plant Variations}

The likelihood of tube bundle uncovery is dependent on the specific steam generator geometry and the steam generator liquid mass at normal operating conditions. This can be illustrated by reference to Figure 28 . Dimension $A$ on this figure is the height of the top tube above the tube sheet. Dimension $B$ is the height of the normal water level above the top of the top tube. Other things being equal, a steam generator with a longer $A$ dimension will require more liquid mass to cover the tubes on a collapsed or nearly-collapsed liquid basis. Whether or not this extra liquid mass is present at normal operating conditions is partly a function of dimension B. 
As an example, comparison of the geometries of the Surry Series 51 steam generator with the $\mathrm{H}$. B. Robinson Model $44 \mathrm{~F}$ steam generator indicates that dimension $A$ is about four feet longer in Surry whereas dimension $B$ is nearly the same for the two plants. Hand calculation estimates demonstrate the significance of this difference. For H. B. Robinson the normal operating mass of liquid is roughly at, or slightly above, that required to cover the U-tubes on a collapsed level basis. In the case of Surry the initial liquid mass is insufficient to cover the tubes on a collapsed level basis. Although caution must be taken in interpreting the above information due to significant uncertainties in masses at normal operating conditions and other geometric differences between the steam generators, it can be said that the likelihood of post-trip tube bundle uncovery is a function both of specific steam generator geometry and the normal operating mass of the steam generator. 


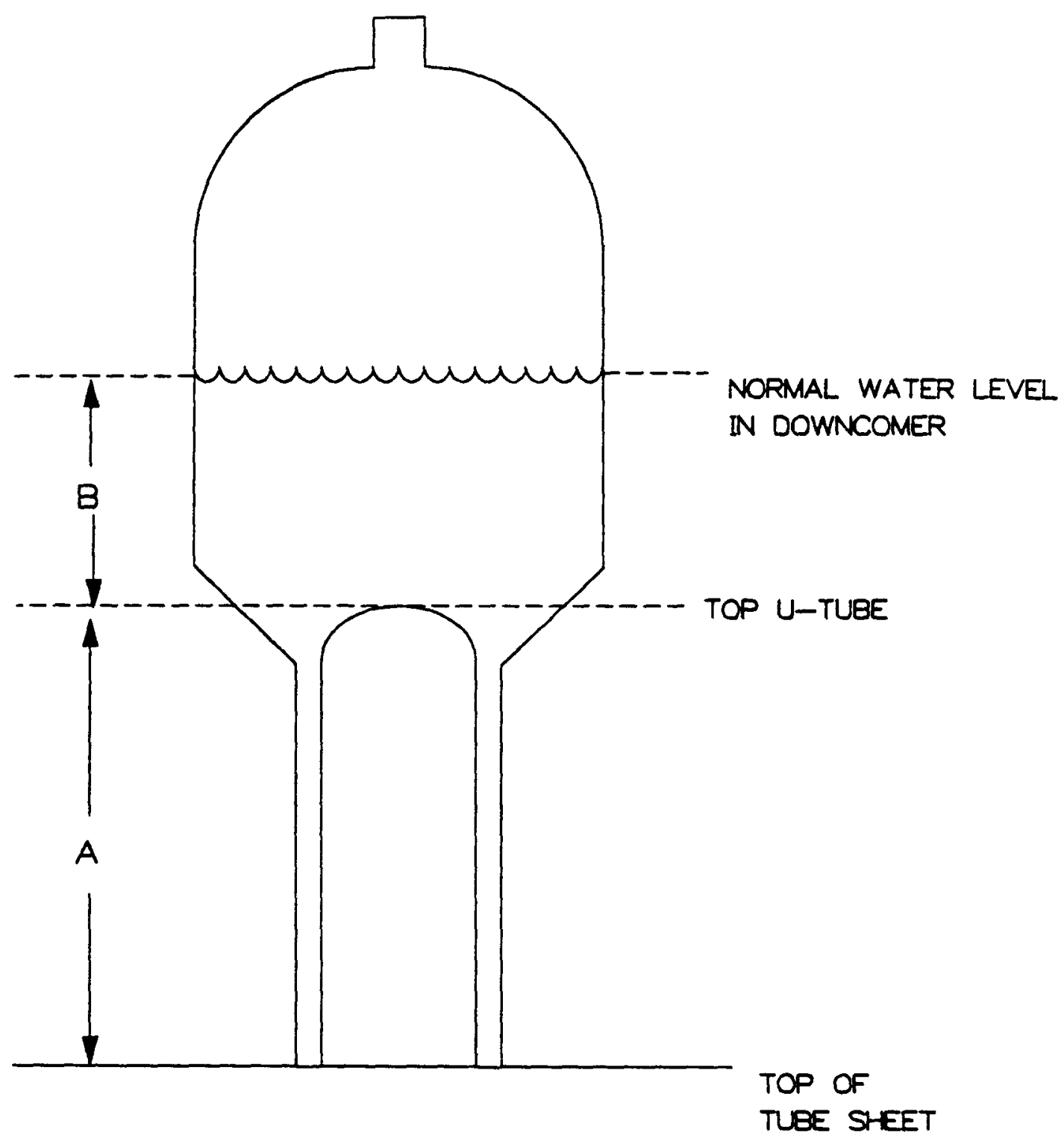

y
8
8
v

Figure 28. Steam generator schematic. 


\section{CONCLUSIONS}

The following conclusions are derived from the analyses presented in this report.

1. For a SGTR with loss of offsite power, iodine present in the secondary steam phase is transported to the environment in the steam released through secondary PORVs and/or SRVs.

The RELAP5 calculation indicated that steam release due to secondary boiling continued for about $500 \mathrm{~s}$ following reactor trip. After secondary boiling had terminated, continued feedwater injection resulted in additional steam (and iodine) release due to volumetric displacement of a steam bubble in the steam generator.

2. The RELAP5 calculation indicated that the post-trip secondary mixture level was sufficient to maintain continuous coverage of the $U$-tubes.

The RELAP5 result was supported by a hand calculation using the method of Sun.

3. Atmospheric iodine release is sensitive to the assumed value of the partition coefficient.

For the transient scenario analyzed, a decrease in the value of the partition coefficient from 100 to 1 (on a mass basis) resulted in an increase in iodine release from $4.91 \times 10^{-8} \mathrm{~g}(0.006 \mathrm{Ci})$ to $2.03 \times 10^{-6} \mathrm{~g}(0.25 \mathrm{Ci})$. Hand calculation estimates of integrated thyroid dose at the site boundary ranged from 0.002 rem $(P=100)$ to 0.076 rem $(P=1)$, for the case of an initial RCS iodine activity of 1 microcurie/g with no iodine spiking. For an assumed pre-accident iodine spike, dose estimates ranged from 0.036 rem $(P=100)$ to 1.5 rem $(P=1)$.

4. The assumption of post-trip U-tube uncovery on a collapsed liquid level basis had a minor effect on the amount of iodine release. 
After reactor trip a calculated three minutes were required for auxiliary feedwater to supply enough liquid to recover the $U$-tubes on a collapsed level basis. Assuming a mixing fraction of 1.0 for this period (primary break fluid jetted directly into the separator), resulted in a $20 \%$ increase in the amount of iodine release.

5. Atmospheric iodine release is dependent on operator actions.

The present analysis assumed no operator action to throttle the auxiliary feedwater. Excess liquid level in the steam generator resulted in atmospheric release due to volumetric displacement of the secondary steam bubble. However, throttling of the auxiliary feedwater could result in additional release due to secondary boiling.

Atmospheric steam release depends on the timing of operator actions to: isolate the affected steam generator, cool the primary RCS by secondary depressurization, and depressurize the primary system below the pressure of the affected steam generator.

6. The likelihood of U-tube uncovery is dependent on specific steam generator geometry and normal operating steam generator secondary liquid mass.

A comparison of the Surry Series 51 and the H. B. Robinson Model 44F steam generators indicated a greater likelihood of tube bundle uncovery, on a collapsed level basis, for surry. In part, this was due to differences in the geometry and normal operating secondary liquid mass between the two steam generators. 


\section{REFERENCES}

1. J. Hopenfeld, Radioactivity Transport Following Steam Generator Tube Rupture, U.S. Nuclear Regulatory Commission, NUREG-1108, March 1985.

2. J.R. Wolf, Steam Generator Tube Rupture Transient Radioactivity Tracking Capability for a TRAC RESAR-3S Steam Generator Model JRW-20-87, INEL letter report to J. Hopenfeld, May 1987.

3. Virginia Power Company, Surry Power Station Updated Final Safety Analysis Report, Docket 05000280, 05000281, July 16, 1982.

4. Westinghouse Owners Group, Emergency Response Guidelines, Volume E-3, ECA-3, Low Pressure Version, Revision 1, September 1, 1983.

5. C.D. Fletcher et al., RELAP5 Thermal-hydraulic Analyses of Pressurized Thermal Shock Sequences for the H. B. Robinson Unit 2 Pressurized Water Reactor, EG\&G Idaho Inc., NUREG/CR-3977, EGG-2341, April 1985.

6. Westinghouse Electric Corporation, et. a1., Coincident Steam Generator Tube Rupture and Stuck-Open Safety Rel ief Valve Carryover Tests (MB-2 Steam Generator Transient Response Test Program, NUREG/CR-4752, March 1987 .

7. U.S.N.R.C. Standard Review P1an, NUREG-0800, Rev. 2, 1981.

8. K.H. Sun et al., "The Prediction of Two-phase Mixture Level and Hydrodynamically-Controlled Dryout Under Low Flow Conditions," International Journal of Multiphase Flow, Vol. 7, No. 5, pp. 521-543, 1981 .

9. J.P. Cunningham and H.C. Yeh, "Experiments and Void Correlation for PWR Smal1-break LOCA Conditions, " Transactions of the American Nuclear Society, Volume 17, p. 269, 1973.

10. C.B. Davis and J.E. Blakely, Analyses of Steam Generator Tube Ruptures in Arkansas Nuclear One Unit 2, EGG-NTAP-6226, April 1983. 
11. J.P. Adams et a1., Risk Associated with a Spectrum of Steam Generator Tube Ruptures (Scoping Task Report), EGG-SSRE-8187, July 1988.

12. "International Commission on Radiological Protection Publication 30, Parts 1 - 3 with supplements A, B, C," Annals of the ICRP Vol. 2-8, Pergamon Press, Oxford, England.

13. Carolina Power and Light Company, H. B. Robinson Unit 2 Final Safety Analysis Report, Docket 50-261, July 1982.

14. Tennessee Valley Authority, Sequoyah Nuclear Plant Final Safety Analysis Report, Docket 50-327, 50-328.

15. Westinghouse Nuclear Energy Systems, Resar 35 Reference Safety Analysis Report.

16. D. Dodronich, Steam Generator Tube Rupture Analysis for Zion-1, LA-SSTS-TN-81-2, 1981 .

17. B. Nassersharif, Analysis of Steam-Generator Tube-Rupture Events Combined with Auxiliary-Feedwater Control-System Failure for Three Mile Island Unit 1 and Zion Unit 1 Pressurized Water Reactors, LA-UR-85-1773, 1985. 
The RELAP5 model of the Surry Plant was developed to include the major components necessary to model severe accidents such as station blackouts (Reference A-1). The reactor vessel, three coolant loops, three steam generators, and the pressurizer were modelled. Modelling information was obtained from References A-2 and A-3.

The reacror vessel nodalization is shown in Figure A-1. The downcomer, lower head, lower plenum, core, core bypass, upper plenum, and upper head were modelled.

The three coolant loops were modelled individually. A nodalization diagram of the loop with the pressurizer is shown in Figure A-2. The other loops were identical to the one shown except the pressurizer was not included, and the steam generators were less finely noded.

The steam generator model included the tubes, downcomer, riser, separator, steam line, main and auxiliary feedwater systems, main steam isolation valve, PORVs, and SRVs. The metal masses associated with the steam generator walls and internals were modelled, with the outer surface of the steam generator assumed to be adiabatic.

The broken steam generator tube was simulated by modelling a single tube analagous to pipe 408 of Figure A-2. The break was placed at the junction separating the tube upflow side and the downflow side. Both break junctions (from the upflow side and into the downflow side) were connected to secondary volume 477 . Heat transfer was represented between each primary cell and the adjacent steam generator secondary cell.

For the separate effects runs, the steam generator shown in Figure A-2 was used. The supplied boundary conditions were: hot leg temperature, hot leg pressure, hot leg mass flow, and cold leg pressure. 


\section{References}

A-1. P.D. Bayless, Natural Circulation During a Severe Accident: Surry Station Blackout, EGG-SSRE-7858, September 1987.

A-2. J.D. Burtt, Audit Calculations for a Main Steam Line Break in North Anna, Unit 2 Using the RELAP5 Computer Code, EGG-NTAP-6082, November 1982.

A-3. Virginia Power Company, Surry Power Station Updated Final Safety Analysis Report, Docket 05000280, 05000281, July 16, 1982. 


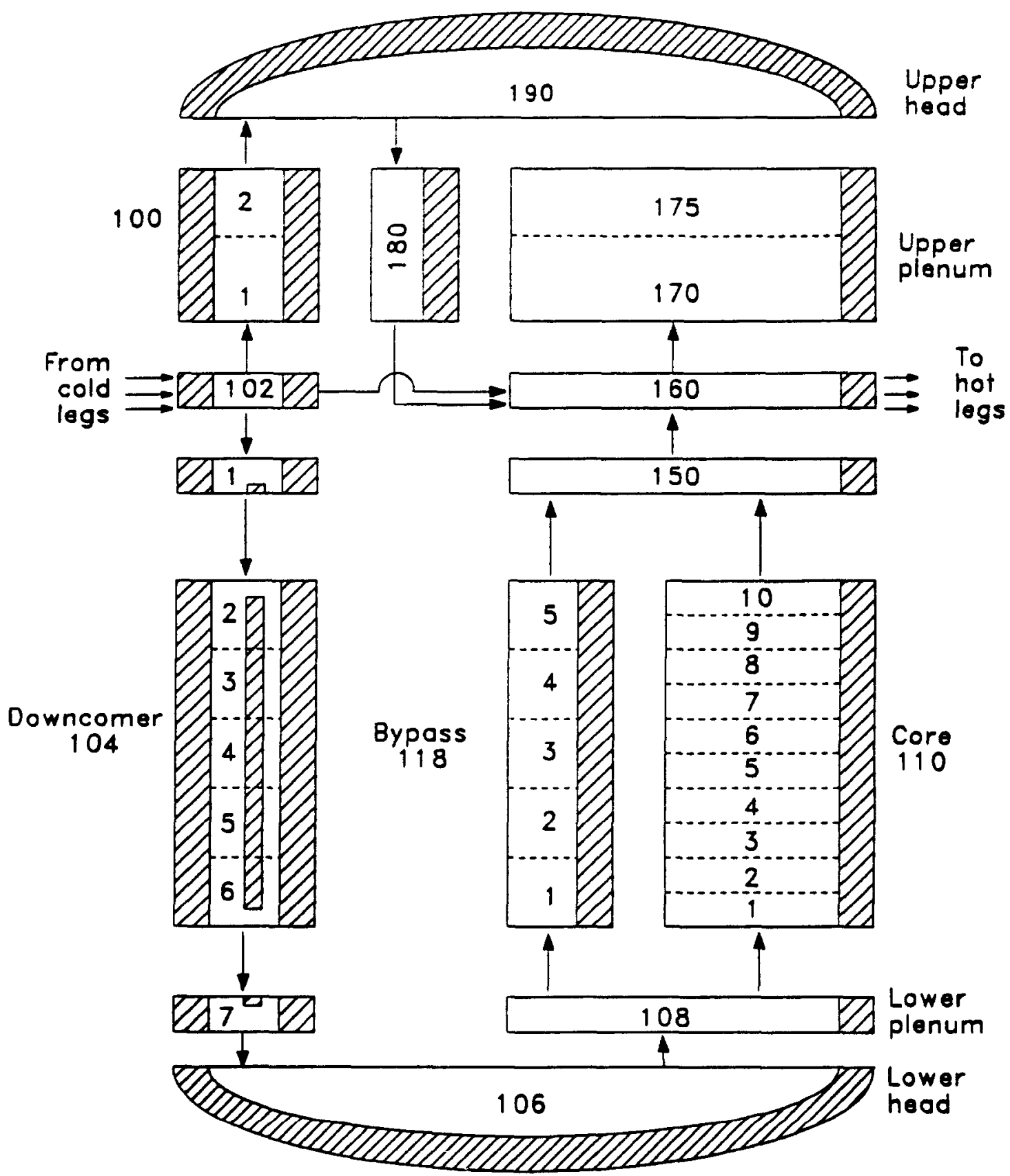

P428 ST-0245-03

Figure A-1. Nodalization of the Surry vessel. 


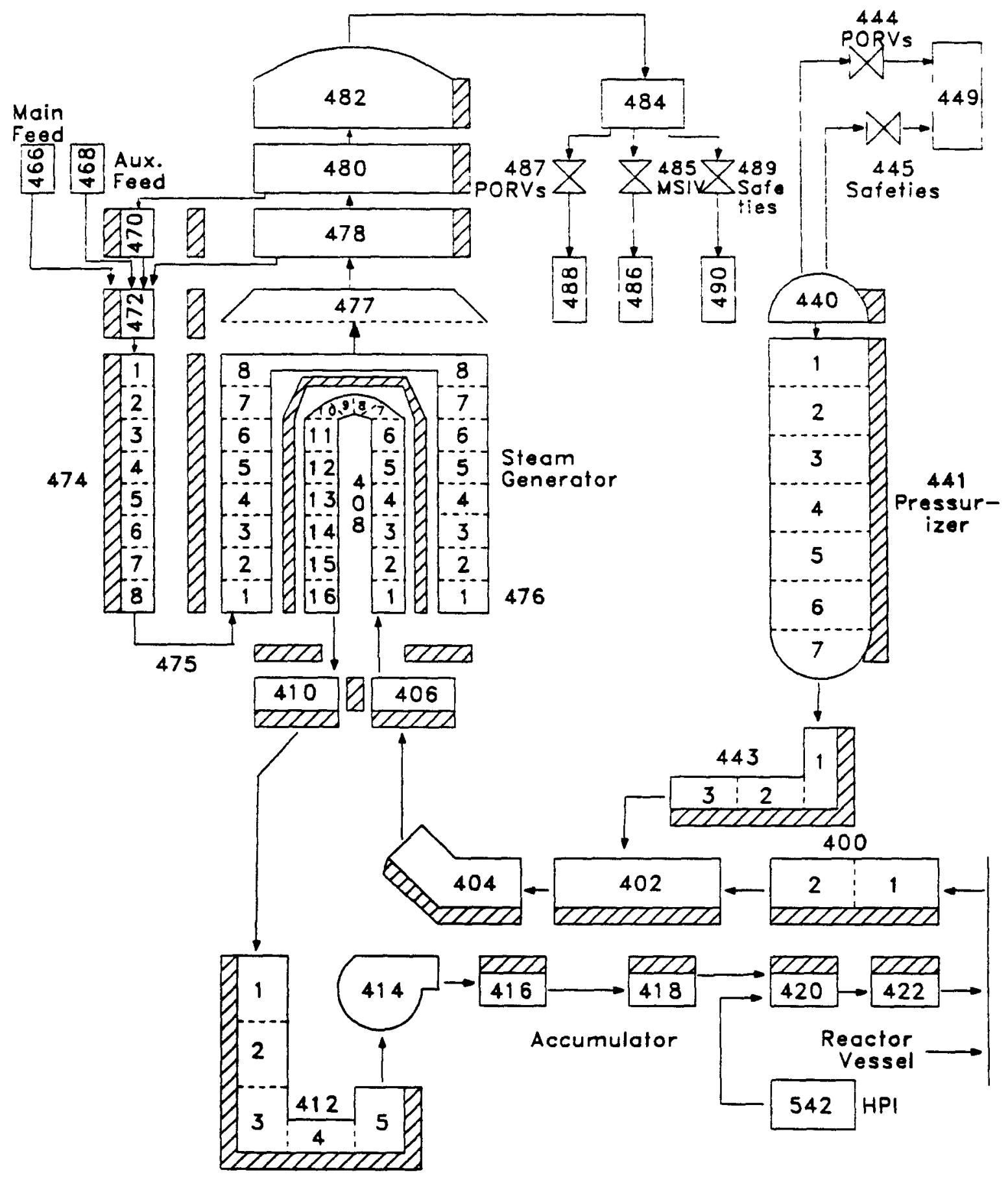

Figure A-2. Nodalization of the pressurizer coolant loop for the Surry RELAP5 calculation. 


\section{APPENDIX B}

NOMENCLATURE

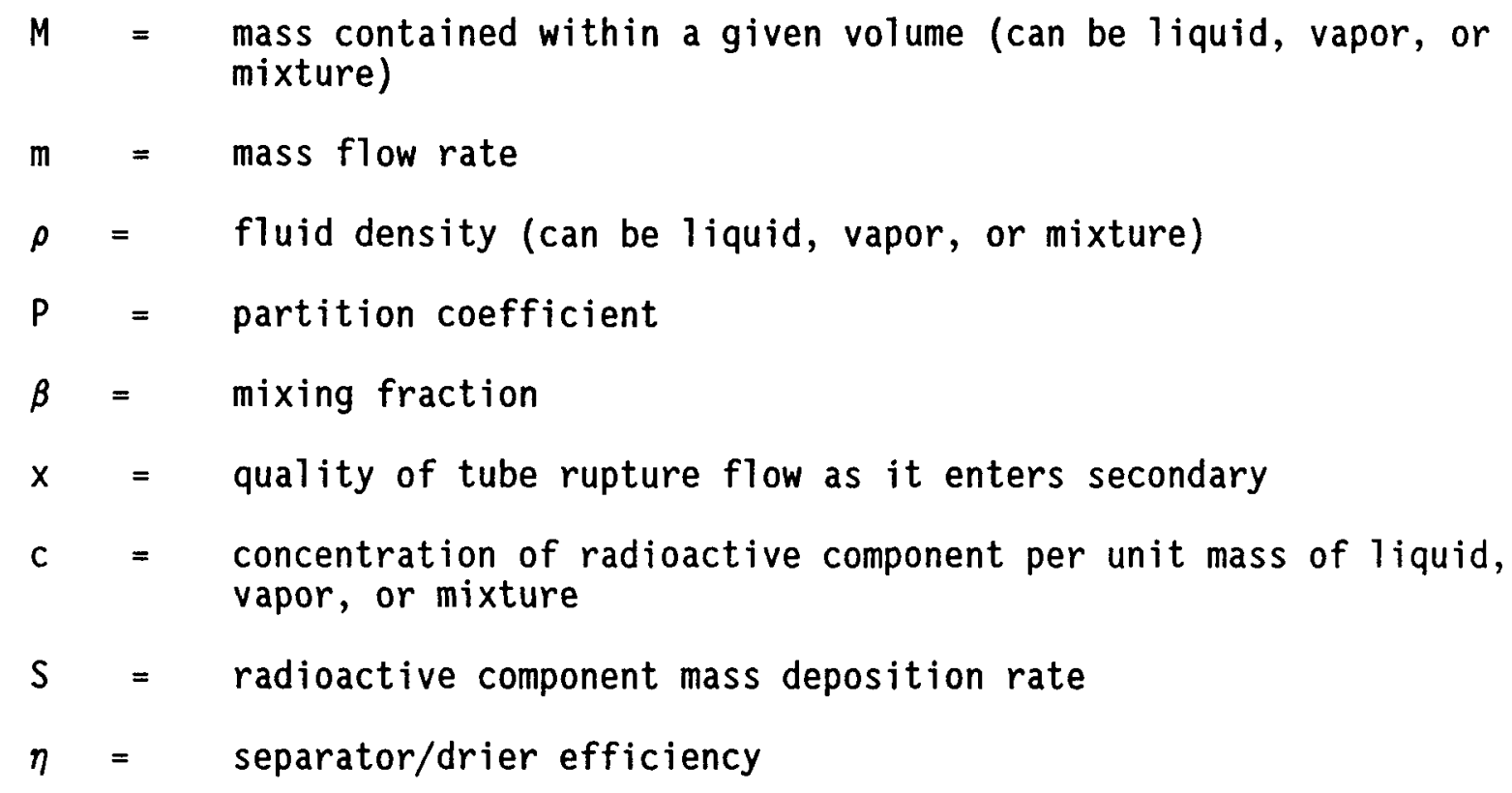

\section{Subscripts}

$H=$ quantities associated with the two-phase portion of the heater/riser region

$D=$ quantities associated with the downcomer region

$F=$ feedwater/auxiliary feedwater

$E=$ quantities associated with the separator/drier-to-downcomer flow path

$S=$ quantities associated with the separator inlet

$0=$ quantities associated with the separator/drier-to-steam dome flow path

$1=1$ iquid phase

$g \quad=\quad$ vapor phase

$P \quad=\quad$ quantities associated with the primary fluid 


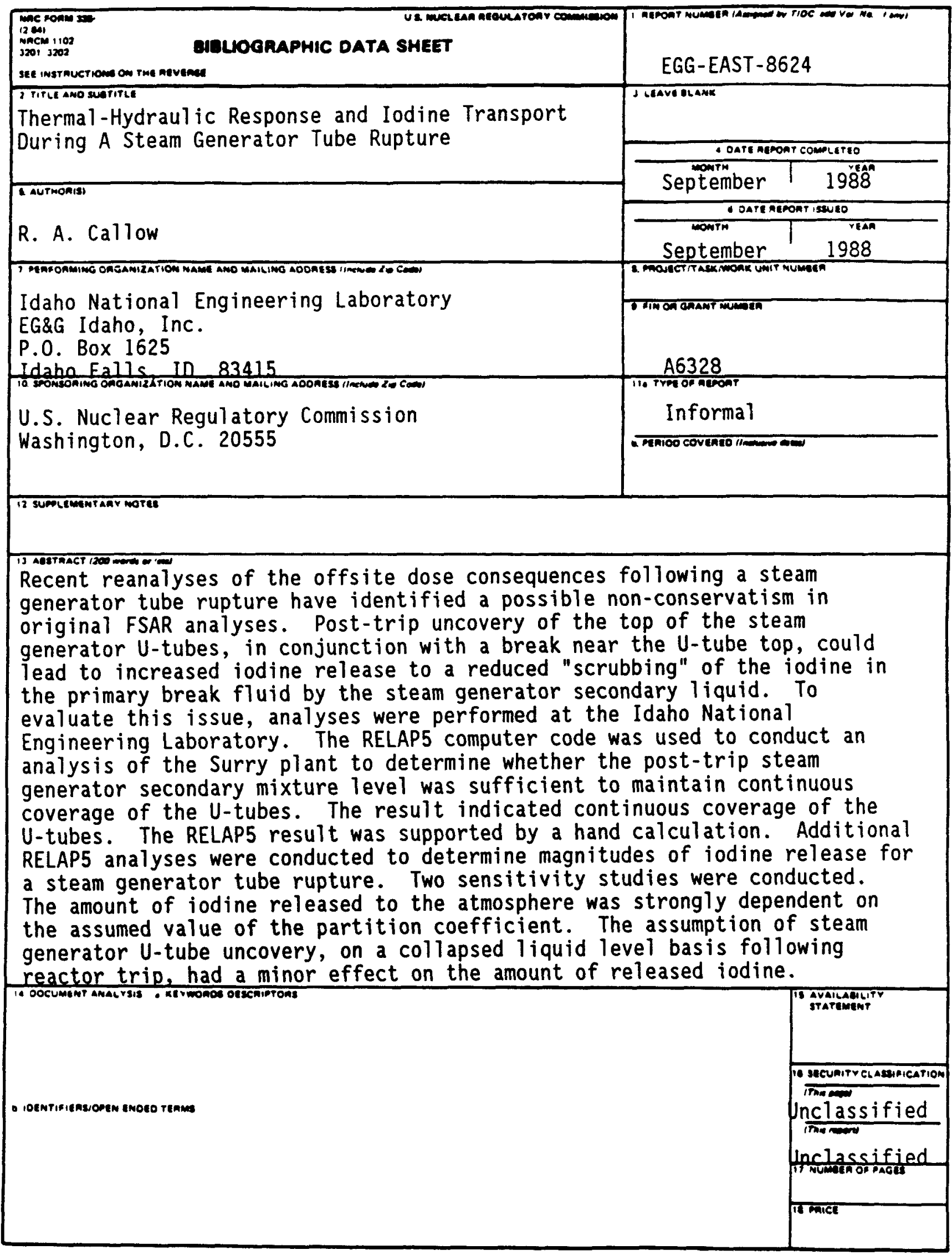

